\title{
Return Migration and the Transfer of Gender Norms: Evidence from the Middle East ${ }^{*}$
}

\author{
Michele Tuccio ${ }^{\dagger}$
}

Jackline Wahba ${ }^{\ddagger}$

\begin{abstract}
Does international return migration transfer gender norms? Focusing on Jordan, an Arab country where gender inequality and emigration rates are high, this paper exploits unique data in which detailed information on female empowerment allows us to construct several measures of social norms in Jordan on the role of women, female freedom of mobility, and female decision-making power. Controlling for both emigration and return migration selections, we _nd that women with a returnee family member are more likely to bear traditional gender norms than women in households with no migration experience. Further analysis shows that results are driven by returnees from more conservative Arab countries, suggesting a transfer of conservative norms from destinations with highly traditional gender roles. We also show the implications of our results beyond perceptions for several economic and development outcomes, such as female labour force participation, education and fertility.
\end{abstract}

JEL classification: F22; J16; O15; O53.

Keywords: International return migration, Gender inequality, Transfer of norms.

\footnotetext{
* A previous version of this paper circulated under the title "Can I Have Permission to Leave the House? Return Migration and the Transfer of Gender Norms.”

We would like to thank Simone Bertoli, Raj Chowdury, Amelie Constant, Corrado Giulietti, Martin Guzi, Maryam Naghsh Nejad, Mariola Pytlikova, Hillel Rapoport, Ibrahim Sirkeci, and Yves Zenou for helpful discussion. We are also grateful to seminar participants at the World Bank, UNU-WIDER, Royal Economic Society, Georgetown University/IZA, Columbia University, University of Oxford, University of Southampton, EUDN, ISTAT, NOVAFRICA, and Masaryk University for useful comments. Tuccio acknowledges financial support from the Economic and Social Research Council (ESRC). Any remaining errors are ours.
}

†UMR DIAL, LEDa, IRD-Université Paris-Dauphine, Paris, France. ESRC Centre for Population Change (CPC). Email: michele.tuccio@ird.fr

${ }^{\ddagger}$ Corresponding author. Economics Department, School of Social Sciences, University of Southampton, Southampton, SO17 1BJ, United Kingdom. Tel: 442380593996, E-mail: j.wahba@soton.ac.uk 


\section{Introduction}

There has been an increasing awareness of the importance of gender equality for greater economic development (see for example Duflo (2012) for a survey on the relationship between female empowerment and economic development). Social institutions and norms frame the gender roles at the roots of a society and the distribution of power between men and women in the household and in the economic and political landscapes (Alesina et al. (2013); Meyersson (2014)). If these social norms deprive women of their autonomy and capabilities, then a gender gap is created between men's and women's opportunities, and consequently between their respective outcomes (Field et al. (2010)).

Exposure to different practices and attitudes towards women within a country - such as exposure to female leaders - has been seen as an important channel through which gender norms are shaped (Beaman et al. (2009)). This paper demonstrates that, through exposure, international migration may also act as a channel of norms transmission. In fact, values and behavior in destination countries influence the set of norms that migrants have acquired at home, assimilating their beliefs to those of the natives. When migrants visit or return to their origin countries, they bring back the newly acquired norms and those may spread around their communities.

This paper presents a three-fold contribution to the economic literature. While political accountability and fertility norms have been found to be promoted in origin countries by international migrants (Spilimbergo (2009); Batista and Vicente (2011); Beine et al. (2013); Bertoli and Marchetta (2015)), whether migration modifies gender norms is still an unanswered question. This paper therefore fills the existing gap by studying whether return migration acts as a channel of norms transmission and reduces gender inequality 
in social norms at home.

Secondly, this paper is among the first ones to construct a composite index of gender social norms at micro level. ${ }^{1}$ Whilst previous works concentrated on outcomes variables, such as education or employment status, we argue that gender gaps in opportunities are indeed at the root of the consequent inequalities in outcomes. Hence, focusing on traditional norms and social institutions is key to understanding gender inequality.

A further contribution of the present study is to emphasize the importance of controlling for both selection into emigration and selection into return migration when comparing returnee and non-migrant households, as both emigrants and returnees are self-selected on the basis of unobservable characteristics. Adopting a multi-equation mixed system in a Conditional Mixed Process (CMP) framework to control for selection into migration and selection into return migration, we demonstrate that estimates are biased if the double selectivity is not taken into account.

We focus on the case of Jordan, a Middle-Eastern, non-oil middle-income economy where both gender inequality and emigration rates are high. Our analysis is based on the "Jordan Labor Market Panel Survey 2010" (JLMPS 2010), a nationally representative household survey of more than 5,100 households and about 25,000 individuals in 2010 .

Although women's educational attainment gradually reached the level of their male counterparts, Jordan has still one of the lowest female labour force participation rates in the world at 15 percent in 2010 (Assaad et al. (2014a)). The World Bank (2005) gender assessment report confirms that women's economic role in Jordan does not correspond to the pattern seen in similar middle-income countries. De facto, societal and familial pressures limit women's greater position in the economy. For example, while entering

\footnotetext{
${ }^{1}$ Recent exceptions are the work of Assaad et al. (2014a) and Dhar et al. (2015).
} 
certain public spaces, such as administrative offices, without male presence is considered unacceptable (OECD (2014)), some women's movements may still be restricted on a dayto-day basis: 14.4 percent of women questioned in the 2007 Demographic and Health Survey (DHS) reported that they needed their husbands' permission to visit their own family or relatives.

In addition, women are still not equal to men before the law. For instance, Kelly (2010) reports that, under the Personal Status Law, all single women (whether divorced, widowed, or never married) under 30 are considered to be legal minors, and are under the guardianship of a male relative. Gender inequality is reflected in Jordan's low placement in human rights indices: under the 2011 Human Development Index (HDI), Jordan is ranked in 95th place (out of 187 countries), with a score of 0.698 . The Gender Inequality Index value is 0.456 placing it at 83 out of 146 countries, while it is ranked 117 th in the 2011 Global Gender Gap Index.

At the same time, Jordan is a labor exporter economy, with a migrant population ratio reaching 11.2 percent in 2005 (Xu and Ratha (2008)). This is much higher than the 3.3 percent emigrant population average share for middle-income countries. More importantly, as pointed out by Wahba (2014), almost every one in 10 households in Jordan had a return migrant in 2010 as the majority of migration is temporary and destined to neighboring Arab countries.

This paper aims to explain the aforementioned stylized facts by examining the role of return migration and its impact on gender norms, female freedom of mobility, and women's decision-making power in the family. Results show that return migrants transfer conservative norms from destination countries with highly traditional gender roles, which 
widen already existent gender gaps in Jordan. Our findings confirm that social norms are a key determinant of the failure of convergence in labour market outcomes, perpetuating extremely low female labour force participation in Jordan.

The remainder of the paper is structured as follows: section 2 provides a brief review of the current scholarly understanding of the "transfer of norms"-migration nexus. Section 3 introduces data, summary statistics, and the construction of the composite indices of gender norms. Section 4 discussed the empirical approach and econometric framework, whilst the estimation results are provided in section 5. Section 6 concludes.

\section{Migration-induced transfer of norms}

While the analysis of the determinants of international migration has received great attention over the last years, a growing strand of the literature is now focusing on the possible externalities that migration may bear on sending areas. The so-called "transfer of norms" literature assumes that international migration drives institutional changes in origin countries. Essentially, migrants living in a foreign country and returnees stream new ideas and narratives to their community members, which consequently shift the social norms and institutions in place at home.

Economic studies on the "transfer of norms"-migration nexus have started to grow after the work of Spilimbergo (2009) on democracy and foreign education. Using data for 183 countries over the period 1960 to 2005, he finds that foreign-educated individuals play a role in fostering democracy in their home countries. Similarly, Batista and Vicente (2011) use a simple voting experiment in Cape Verde to demonstrate that international migration experiences promote better institutions at home by boosting demand for polit- 
ical accountability. Other recent contributions use electoral data from Moldova (Barsbai et al. (2017)) and Mali (Chauvet and Mercier (2014)) to estimate a migration-induced transfer of political norms.

Fertility choices have also attracted much attention over the last few years. In particular, Beine et al. (2013) argue that, through the transfer of norms, migration from high-fertility sending countries to low-fertility destination countries reduces fertility in the former. Conversely, Bertoli and Marchetta (2015) demonstrate that Egyptian married couples where the husband has a past migration experience in another Arab country have a significantly larger number of children than stayers.

Much less attention has been given to the relationship between migration and gender inequality in origin countries. At macro level, Lodigiani and Salomone (2012) investigate the effect of international migration on the parliamentary participation of left-behind women. They show that total international migration to countries where the share of female parliamentary seats is higher increased source country female political voice between 1960 and 2000. The authors argue that such results may be linked to the informational role of international migrants, who can transfer foreign values, reshape attitudes and create new norms about women in the origin country. A broader concept of gender inequality is adopted by Ferrant and Tuccio (2015), which focus on overall gender discrimination in developing countries using the Social Institutions and Gender Index of the OECD Development Centre. Their cross-country analysis of bilateral South-South migration flows finds that migration may either entrench or challenge gender inequality according to the level of social institutions in the host country.

To our knowledge, micro-economic evidence on the impact of international migration, 
and in particular return migration, on female empowerment is rather sparse. Although there are a few sociological works analyzing the role of migration on gender equality, most studies look at the position of female stayers when their male partners are currently abroad. Hence, regardless of the sign, the effect can be due to a change in household composition, with left-behind wives taking up the role of the absent husbands. However, the change in responsibilities and decision-making power among women can be temporary in nature, since men may assume their traditional, patriarchal roles as soon as they return (De Haas and Van Rooij (2010)). The present paper is therefore the first economic study to analyze return migrants and their effect on gender norms.

\section{Migration and gender norms in Jordan}

\subsection{Data and descriptive statistics}

International migration has played a key role in shaping Jordan's economic and social landscapes. Since the 1973 increase in international oil prices, large flows of Jordanians emigrated towards the neighboring GCC states. According to the national Ministry of Labor, 140,722 Jordanians were still residing in oil-producing countries in 2009, 39 percent of whom in the United Arab Emirates, 36 percent in Saudi Arabia and 13 percent in Kuwait. Return migration is also an important feature of Jordanian society, with approximately 11 percent of the households having a returnee among their members (Wahba (2014)). Looking at the characteristics of returnees by destination suggests that emigrants to Arab countries have similar education levels to those who went to the West: roughly 40 percent of Jordanian emigrants to both destinations have secondary education or higher (Wahba 
$(2014))$.

The analysis of this paper is based on the recently-released "Jordan Labor Market Panel Survey" (JLMPS 2010), which was administered by the Economic Research Forum (ERF), the Department of Statistics in Jordan (DoS) and the National Centre for Human Resources Development (NCHRD) in the period from December 2009 to June 2010 (OAMDI (2016)). The JLMPS 2010 is a nationally representative data covering about 5,100 households and 25,000 individuals and has rich information on demographic characteristics and labour market experiences.

Despite being the initial wave of what is to be a longitudinal survey, the JLMPS 2010 contains a number of distinctive features which are key for the present study. Firstly, retrospective questions on labour and residence mobility allow us to identify return migrants. $^{2}$ Secondly, a unique characteristic of this survey is that it provides information on current migrants, including education and employment history, year of migration and destination country which allows us to control for selection into emigration. ${ }^{3}$ Lastly, and a real peculiarity among labour market surveys, the JLMPS 2010 includes important information about women's status in the society. Specific questions on the self-perceived role of women, freedom of mobility and the extent to which women can take decisions in their families can be used in order to proxy for the long-lasting codes of conduct, norms, traditions, informal laws that might contribute to gender inequalities in all spheres of life.

\footnotetext{
${ }^{2}$ Note that such retrospective questions allow us to reconstruct the residence of the individual up to the last two movements, and does not permit to know the full life history of migration.

${ }^{3} \mathrm{~A}$ common caveat of migration data is the lack of information on households which have emigrated in their entirety, and therefore are not interviewed at the time of the survey. However, in the Jordan case the eventual bias may be considered rather small, since migration towards Gulf countries is mostly temporary in nature (David and Marouani (2013)), as also supported by the fact that almost 38 percent of current migrants in our sample has left Jordan in the last two years. At the same time, more than 80 percent of current migrants have visited the left-behind household in the last two years, assuring the reliability of the information provided by the interviewees.
} 
Our sample is comprised of 4,098 women aged 15-60 years old, among whom 838 live in households with return migrants and 3,260 have no migrants in their families. Among women in return migrants households, $46 \%$ of our sample are wives, $32 \%$ are daughters, and $22 \%$ are others. Most returnees are males, either husbands (if the woman interviewed is married) or fathers (if the woman interviewed is unmarried). Only 5 percent of returnees in our sample went to non-Arab countries, whilst the remaining 95 percent migrated towards Arab countries. ${ }^{4}$ For this reason, we restrict our analysis to migrants towards the Arab region.

Table 1 compares individual characteristics of women with a returnee among their family members and women from non-migrant households. Data confirms the existence of a paradox in Jordanian society: more than 40 percent of women have a secondary or higher degree, but only 11-14 percent is formally employed. These figures suggest that underlying social norms on what is deemed acceptable for women limit their employment at full capacity. Approximately one in every three women is married to a family member, reflecting the role of norms and informal institutions in Jordan. Interestingly, women with a returnee are on average older and more educated than those in households with nonmigrant, and also their mothers have achieved greater educational attainments. Moreover, having a returnee is often linked with a much greater probability of living in cities.

\subsection{Construction of composite indicators}

Most previous studies constructed cross-country measures of broad concepts of gender norms, including outcome variables such as educational and employment status, poverty and political participation (Ferrant (2014)). There is very little literature on the construc-

\footnotetext{
${ }^{4}$ Non-Arab countries are mainly European countries, the US, Canada and Australia.
} 
tion of composite indicators of gender inequality at micro level, and even scarcer literature focusing on conservative social norms rather than on outcomes (a recent exception is Assaad et al. (2014b)).

However, the use of household and labour market surveys often provides categorical and binary questions that need to be aggregated into composite indices in order to have an overall view of the dimensions under analysis. We exploit three sets of variables included in the JLMPS on three different aspects of gender equality, administered to all females in the age group 15-60 (men have not been interviewed on such questions about female status, hence the present analysis can be undertaken only for women).

We first look at the self-perceived role of women (RWI). The analysis will be based on 10 questions on what women think should be their role in the society. Queries involve whether girls should be treated equally to boys, whether female employment should be encouraged as well as female education, and whether women should get leadership positions in the society.

We then turn to analyze gender outcomes in the household, such as women's freedom of mobility (FMI). Variables on whether women need permission to move are exploited to have a sense of the freedom of mobility at family level. Specifically, women are asked if they need prior permission to go to the local market, to the doctor or to visit friends and relatives. We also make use of 9 variables on female decision-making (DMPI) to understand the extent of women's bargaining power and agency within the family. Questions include who has the final say on making household purchases, getting medical treatment and sending children to school. We argue that overall these three measures, 23 variables, effectively represent the underlying gender inequality in Jordanian society. 
Several approaches can be adopted to aggregate our variables into composite indicators of gender equality. Equal weights have been extensively used for their simplicity and apparent objectivity. They are often preferred since there may be no obvious reason for valuing one variable more or less than the others. In our case, although singly the variables had a categorical response, they have been re-coded in order to take binary value. The simple average of the respectively 10, 4 and 9 variables has then been calculated in order to have 3 different measures of gender norms in Jordan. The proposed index is transparent and easy to understand: it can take values from 0 , corresponding to conservative social norms, to 1, meaning complete gender equality.

On the other hand, average mean implicitly assigns greater weights to the variables with larger variance and higher correlation with each other (Ferrant (2014)). Since the imposition of numeric equality is completely arbitrary, the use of statistical procedures to determine weights should be favoured (Filmer and Pritchett (2001)). Principal Components Analysis (PCA) is one of the most common weighting techniques, which extracts from a group of variables those orthogonal linear combinations that size the common information most accurately. Essentially, gender equality can be seen as complex unobserved phenomenon that we want to estimate using a set of observed proxies. The goal of PCA is to aggregate the variables that we assume can best describe gender equality in such way that they represent successfully the latent complex index. Weight determined on the basis of PCA represents the relative contribution made by the variables to the variance of the composite index. Greater weights are assigned to variables which contribute to larger shares of variation. The advantage of this methodology is to estimate the set of weights that explains the largest variation in the original variables. 
Nonetheless, recent studies have emphasized that Principal Component Analysis (PCA) was originally designed for continuous variables, whilst Multiple Correspondence Analysis (MCA) should be preferred to analyze qualitative, categorical and binary variables (Ferrant (2014)). Conversely to PCA, which estimates the absolute weight of each component, MCA studies their relative frequencies.

Constructing composite indicators using MCA involves building an indicator matrix of 1 and 0 values which describes the various gender norms under analysis. Importantly, every variable is disaggregated into mutually exclusive and exhaustive dummies, one for each category. In other words, each woman (or row) will have 1 in one and only one category (or column), and 0 in all the others. Let's consider a matrix with $Q$ questions, $C_{q}$ categories for question $q$, and $C$ total categories. The main difference between PCA and MCA is that in the latter every row has to answer "1" to one category in each question, that is, the categories represent all possible answers for the given question $q$. Consequently, each row in the matrix must have a total of $Q$. In the former, instead, the redundant category for each question is omitted (Booysen et al. (2008)).

For the aforementioned reasons, we undertake our analysis using MCA, but we test the robustness of our results using both PCA and equal weights. Our composite indices of gender norms are given by:

$$
Y_{i}^{j}=A_{i 1} W_{1}^{j}+A_{i 2} W_{2}^{j}+\ldots+A_{i q} W_{q}^{j}
$$

where $Y_{i}^{j}$ is the value of composite index $Y$ (i.e. Role of Women Index, RWI; Freedom of Mobility Index, FMI; and Decision-Making Power Index, DMPI) for individual $i$ using the weighting technique $j$ (namely, MCA, PCA and equal weights), $A_{i q}$ is the answer of 
individual $i$ to question $q$ and $W_{q}^{j}$ is the weight obtained using the $j$ methodology applied to question $q .^{5}$

\section{Empirical framework}

\subsection{Empirical methodology}

We use the three constructed composite indicators $Y_{i}^{j}$ (Role of Women Index, RWI; Freedom of Mobility Index, FMI; and Decision-Making Power Index, DMPI) through the weighting technique $j$ as our dependent variable in order to estimate the causal effect of international return migration on gender norms in Jordan. The regression specification is:

$$
Y_{i}^{j}=\alpha_{0}+\alpha_{1} R_{i}+\alpha_{2} X_{i}+\epsilon_{i}
$$

$Y_{i}^{j}$ is the gender equality index: $R W I_{i}$ is the self-perceived role of women by individual female $i$, where 0 means high gender inequality and 1 implies perfect gender equality. $F M I_{i}$ is the self-perceived freedom of mobility by individual female $i$, where 0 means no freedom and 1 implies perfect freedom. $D M P I_{i}$ is the self-perceived decision making power by individual female $i$, where 0 means no power and 1 implies perfect power. $R_{i}$ is the return migration variable, a dummy being 1 if the individual has at least an

\footnotetext{
${ }^{5}$ Table 14 in Appendix lists the 10 variables that are used to construct the Role of Women Index (RWI) and the respective weights using PCA, MCA and average mean. Greater weights indicate higher level of female empowerment. Looking at the MCA results, it's worth noting that those components which reflect greater female empowerment contribute positively to the gender equality index, while components that reflect conservative social norms contribute negatively. Similarly, Tables 15 and 16 present the variables and the correspondent weights for the Freedom of Mobility Index (FMI) and for the Decision-Making Power Index (DMPI).
} 
international returnee member from an Arab country within the household. $X_{i}$ is a vector of individual female's characteristics (including age, age squared, marital and employment status, educational attainment, mother's education, a dummy for having at least one child, a dummy for living in a rural area, a dummy for being married to a relative), household characteristics and governorate dummies. $\epsilon_{i}$ is a zero-mean error term. ${ }^{6}$

Selection of migrants is an important concern, since individuals moving across borders are not randomly drawn from the Jordanian population, but they may be self-selected on the basis of unobservable characteristics. Although we control for an array of observable characteristics related to the migrant's and their household's observable characteristics such as age, education, employment, and rural residence, there are potentially unobservable characteristics that might affect the migration decision. For example, open-minded people may be more likely to engage in international migration as well as bear more gender-equal attitudes towards women. At the same time, return migrants might also be a non-random group among migrants (Wahba (2015)). For instance, unsuccessful migration experiences can affect simultaneously the likelihood of returning back home and traditional attitudes and behaviors against left-behind women. Therefore, in order to control for this double selectivity and correctly identify our full model, two valid exclusion restrictions for the emigration and return decisions are needed.

\subsection{Identification}

Following Wahba and Zenou (2012) and Wahba (2015), we adopt as exclusion restriction for the selection into emigration the historical real oil prices for when the individual

\footnotetext{
${ }^{6}$ We have also controlled for whether there was another adult man at the household, and all our results hold.
} 
first entered in the labour market. The underlying rationale is that this variable has a substantial influence on the scale of emigration towards oil-producing countries which adopt employer-driven immigration systems and respond to fluctuations in local economic conditions. While historical real price of oil could affect migration flows by attracting more migrants towards oil-producing countries, it should have no effect on gender norms in Jordan. Specifically, we adopt average oil prices for when the potential migrant individual was 20 years old, arguing that this is the time in which individuals enter in the labour market. In fact, military conscription at the age of 18 was compulsory for all boys with a minimum term of 2 years, until 1999, when it still became voluntary for 2 years. We confirm our hypothesis by exploiting a variable on the age at first job included in the JLMPS. Indeed, the average age at first job in our sample is exactly 20 years old. Age of current migrants, however, is not provided in the JLMPS. Hence for them we take historical oil prices for the year of first cross-border movement.

Figure 1 shows the correlation between historical real oil price and the number of Jordanian emigrants by year. As robustness, we also adopt oil prices for when the potential migrant was 24 years old, which is the normal age of the end of university in Jordan.

It is worth noting that our exclusion restriction would be invalid if variations in historical real oil prices affected also the employment of Jordanian women, and consequently female empowerment in the society. Although Jordan is a non-oil country, and hence international real oil prices should not bear any direct impact on its labour market, there might still be potential threats to the validity of our exclusion restriction if, for example, oil prices affect the local economy and drive prices up, thereby improving female employment. A first argument against this potential concern is that we examine gender 
norms in 2010, while migration took place on average more than 20 years earlier, leaving enough time for such indirect effects of oil prices to fade. Yet it remains plausible that labor market conditions at the start of one's career affect lifetime employment outcomes (wages, unemployment, etc.) and hence also women's careers and empowerment. Yet, it is important to remember that female labor force participation in Jordan is very low at $14 \%$ and declines after marriage, dampening the concerns of this potential threat.

To confirm the validity of our exclusion restriction, we conduct two tests. First, we examine the effects of historical real oil prices of when respondent women first entered the labour market on: (i) women's participation in the labour force in 2010 (at the time of the survey), and (ii) the self-perceived role of women index in 2010 (described below). As Table 17 in Appendix shows, the coefficients of historical oil prices are not statistically significant and are not correlated with either the labour market outcomes of women in 2010 nor their gender attitudes. Secondly, as a further test, we use an alternative exclusion restriction, see section 5.1 below.

Concerns of violation of the exclusion restriction might still remain if there is a strong serial correlation between the evolution of historical real oil prices and gender norms over time. In particular, a potential caveat may be the simultaneous presence of the declining trend in emigrants seen in the 1980s and 1990s and an overall declining trend of conservative norms over time due to a general advancement of the society. However, analyzing Figure 1, we observe an increase in migration flows again in the 2000s, caused by rising real oil prices, and we do not try to explain trends in norms but rather differences between return and non-migrants households in 2010 .

A last potential threat to the validity of this exclusion restriction is if historical real oil 
prices have a direct impact on return migration. The main concern here is whether higher oil prices would change the nature of migration from temporary to permanent migration i.e. lead to no return migration. However, it is well-documented that Jordanian emigration towards the neighboring Gulf is temporary in nature (David and Marouani (2013)). It is the norm that migrants to the Gulf States would receive short-term contracts for 2 or 3 years but those contracts could be renewable. Moreover, a recent study by McKenzie et al. (2014) finds that shocks in destination country GDP have no effect on the duration of the migration experience of Filipino migrants (a large proportion of which works in the Gulf). Figure 2 shows that indeed international real oil prices are uncorrelated with the magnitude of return migration from Arab countries to Jordan in the period under analysis and Figure 3 also reassures us that there is no correlation between oil prices at the time of migration and overseas migration duration. In column 1 of Table 19 in Appendix, we estimate an OLS regression where the probability of return migration is a function of the historical real oil prices. Results confirm that oil prices do not bear a direct impact on return migration.

For the selection into return migration, the exclusion restriction that we have selected is a measure of exogenous shocks that might have induced Jordanian emigrants to come back to their homes. Specifically, we construct a dummy variable being 1 if the migrant was exposed in affected countries during their migration episode to any of the following exogenous shocks. Firstly, we consider the 1967 Arab-Israeli war, which was fought in only six days by Israel and its neighboring countries, but led to thousands of displaced individuals from the war zones. Secondly, we take into account the First Lebanon War of 1982, where thousands of both civilians and military forces died, pushing many labour 
immigrants to return to their origin countries. Iraq's invasion of Kuwait, instead, led to the First Gulf War in 1990-1991, which made inevitable a huge counter-diaspora of migrants towards their home communities. Finally, the Iraq war in 2003 which has lead to the outflows of migrants. As an additional robustness checks, we also adopt a different exclusion restriction exploiting conflict data from the Correlates of War Project. In particular, we focus on all destination countries where Jordanian migrants in our sample went, and construct a dummy being 1 if the migrant has been exposed to any militarized disputes abroad. Albeit slightly less statistically significant, results are robust to the use of this alternative exclusion restriction for the selection into return migration equation. ${ }^{7}$

Indeed, these shocks did not affect the probability of emigration, but only the destination of migration. Figure 4 shows graphically that our chosen military shocks are not associated with a decrease in the magnitude of emigration from Jordan, whilst column 2 of Table 19 in Appendix confirms this econometrically. We argue that past shocks abroad do not have any impact on gender norms at origin in 2010. Finally, it is important to remember that our measures of gender norms captures a number of aspects beyond the labor market such as freedom of mobility, and equality of treatment as we document in more detail below.

\subsection{Econometric model}

Exploiting the unique information on both returnees and current migrants included in the JLMPS, we are able to estimate the following selections equations on the whole

\footnotetext{
${ }^{7}$ All data are publicly available at: www. correlatesofwar. org. Results are available from the authors.
} 
sample of survey respondents (rather than restricting it to women only):

$$
\begin{gathered}
M_{k}=\beta_{0}+\beta_{1} O_{k}+\beta_{2} Z_{k}+\mu_{k} \\
R_{k}=\gamma_{0}+\gamma_{1} S_{k}+\gamma_{2} C_{k}+n_{k}, \mid M_{k}=1
\end{gathered}
$$

In equation $3, M_{k}$ is the linear probability of individual $k$ being an emigrant, whilst $O_{k}$ is the international oil price variable. Controls $Z_{k}$ for the potential migrants and their household include the level of education, the governorate of residence and the employment status before migration. ${ }^{8}$ In the return migration equation (4), $R_{k}$ is the linear probability of being a return migrant, conditional on being an emigrant, and $S_{k}$ represents the shock variable, constructed as previously explained. Controls $C_{k}$ include the migrant's age, age squared, educational attainment, regional characteristics and the destination of the migrants. As Table 18 in the Appendix shows returnees are different from non-migrants, so we explicitly control for those observable differences.

The three linear equations above (equations 2 to 4 ) are estimated simultaneously using Conditional Mixed Process (CMP). ${ }^{9}$ Exploiting limited-information maximum likelihood (LIML), CMP allows the estimation of a multi-equation mixed system in a Seemingly Unrelated Regressions (SUR) framework, where regressors seem unrelated, although their errors can be correlated. ${ }^{10}$ As underlined by Roodman (2011), in a SUR set-up we can

\footnotetext{
${ }^{8}$ As a robustness we also include decade dummies, capturing the decade of migration or the decade when the individual is aged 20 years old to control for time trends.

${ }^{9}$ We have checked the robustness of our results to clustering the standard errors at household level.

${ }^{10} \mathrm{CMP}$ fits a large family of multi-equation, multi-level, conditional recursive mixed-process estimators. The "Multi-level" means that random coefficients and effects (intercepts) can be modelled at various levels in hierarchical fashion. Since the models can also be multi-equation, random effects at a given level are allowed by default to be correlated across equations. E.g., individual and household effects may be correlated across outcomes. Effects at different levels, however, are assumed uncorrelated with each other
} 
estimate parameters equation-by-equation, but their simultaneous assessment is more efficient since it considers the full covariance structure. In our setting, the use of CMP is particularly required as it allows each equation to vary in sample size. Such feature is essential to estimate our system of equations, each of which has a different sample size: indeed, our outcome equation refers to only women answering questions on female status, whilst the selection into emigration is estimated for the whole population, and the selection into return migration is estimated for the subsample of migrants (either current or return). It is also important to note that running a 2SLS however cannot replace the CMP estimation, which aims at addressing selectivity bias rather than endogeneity. In essence our model can be seen as a modified Heckman procedure - as shown in Table 20 in Appendix, rather than as an instrumental variable approach where we control for the double selectivity of out-migration and for return migration. As shown by Wahba (2015) controlling only for return migration biases the estimates of the impact of migration as migrants are a select group compared to non-migrants but also returnees are a select group among migrants. Hence, we control for double selectivity of migration.

\section{Econometric results}

\subsection{Return migration and gender norms}

Our benchmark results are provided in Table 2. When selection issues are not accounted for, having a returnee in the household seems to have a negative, albeit insignificant, impact on the self-perceived role of women (column 1). However, the negative coefficient of return migration becomes statistically significant once we control for selections and with the observation-level errors. See Roodman (2011). 
into emigration and return migration (column 3). Note that, by controlling for emigration selectivity, the estimate grows by an order of magnitude. Interestingly, correcting for selection into return migration, after correcting for selection into migration, instead, improves precision. This stresses the importance of taking into consideration not only the fact that emigrants are not a random sample of the population, but also that those migrants who return home are also selected on the basis of unobservables. ${ }^{11}$ Given we are estimating two selections, the first selection, where lambda is equivalent to sigma 1 multiplied by rho 12 , is the selectivity of out-migration with respect to our outcome of interest women empowerment. The estimates suggest negative selection i.e. unobservables that increase emigration tend to occur with unobservables that lower women empowerment. Similarly the second selectivity of return migration with respect to women empowerment, is sigma 2 multiplied by rho 13, is also negative suggesting negative selection of return migration with respect to women empowerment i.e. unobservables that increase return migration tend to occur with unobservables that lower women empowerment. Finally, rho 23 is the estimated correlation between the migration and return migration errors is positive, indicating that unobservables that raise migration tend to occur with unobservables that increase return migration. In other words, migrants (and returnees even more so) tend to come from the lower end of the distribution with respect to women empowerment attitudes suggesting that ignoring the migration selectivity is likely to overestimate the relationship between migration and women empowerment, and that since returnees are not randomly selected among migrants but indeed negatively selected with respect to women empowerment ignoring the second selectivity would still overestimate the impact

\footnotetext{
${ }^{11}$ Table 20 in Appendix estimate a simple Heckman model with sample selection for emigration. Results suggest the need for correcting for selection, as well as the validity of our exclusion restriction.
} 
of migration.

Our dependent variable is a composite index which aggregates together several indicators on women's perception of their own status in the society compared to men. A value towards 0 implies that women think their position should be greatly different than the one of men, whilst a value towards 1 means that women acknowledge the importance of equality across genders. Overall, our findings in column 3 show that women with returnee family members are less likely to believe that men and women should have an equal position in the society. This indeed suggests a transfer of discriminatory norms from destination countries, a possibility that we will examine further below.

It is important to note that historical international real oil price is a good predictor of the probability of having emigrated in that specific year, while our shock dummy predicts the likelihood of returning home. ${ }^{12}$ Moreover, controls have the expected sign. In particular, being employed or educated improves women's chances to carry more equal social norms, as well as mother's education, since it is a proxy for gender equality in the household. Age is also correlated with greater empowerment, as young girls are allowed less freedoms, but the positive effect of age on empowerment decays with time, and elderly women show to be also confined by traditional patriarchal norms.

Since women's employment status may be endogenous with our proxies of gender norms, specifications have also been undertaken without the employment variable, confirming the robustness of our findings. In addition, the level of education of the head of the household may also be important in establishing the extent of patriarchal traditional norms in place in the family. For this reason, we test the robustness of our results by

\footnotetext{
${ }^{12}$ As a robustness check, we run a simple Heckman selection, Table 20 in Appendix, where both the historical oil price variable and the shocks variable are found to be significant.
} 
including the education attainment of the head of the household as well. Finally we also include assets (see next section) to control for household wealth. All the results are robust and are available from the authors.

In order to test whether our findings are driven by the use of Multiple Correspondence Analysis (MCA), we run the specifications using both Principal Component Analysis (PCA) and assigning equal weights. Table 3 shows the robustness of our results to the different weighting techniques.

Our results show that Jordanian women with a returnee family member have internalized more traditional gender norms. In order to shed additional lights on gender inequality in migrant households, we now look at female freedom of mobility (FMI) as an additional dimension of female empowerment. Results in Table 4 confirm the negative impact of return migration on gender equality at family level in Jordan. ${ }^{13}$

Interestingly the previous research has often regarded decision-making power within the family as a key aspect of female empowerment (Assaad et al. (2014b)), focusing specifically on married women and their bargaining power against other household members, usually husbands. Hence, a strand of the literature pays particular attention to the effect of migration on the decision-making power of left-behind women. For instance, the recent work by Antman (2015) suggests that migrant husbands can hardly monitor the decision-making and resource allocation at home, thereby increasing left-behind wives' responsibilities and empowerment. ${ }^{14}$ However, although during the migration experience the absence of husbands can increase wives' responsibilities, this may be merely due to a

\footnotetext{
${ }^{13}$ We have checked the robustness of our results for married versus unmarried women and our results in Table 4 are consistent.

${ }^{14}$ Spouse strategic responses to changes in monitoring have been confirmed by Ashraf (2009). Exploiting a randomized experiment in the Philippines, Ashraf finds that spousal control affects the decision-making power within the household.
} 
change in household composition. Most men may take back their patriarchal roles when they return back home (De Haas and Van Rooij (2010)). Thus, we restrict the sample to only married women as they might experience more power when the husband is overseas and hence it is important to check whether they retain that power once the husband is back or whether the husband regain his power and even become more traditional in his attitude to check whether those whose husbands are returnees have a negative impact of their decision-making power, Table 5. Interestingly, the estimates support our previous findings, namely a transfer of traditional gender norms from return migration. Finally, we control for whether the women themselves migrated and again find that all our results hold.

As a robustness check, we use single variables rather than composite indices. We examine several variables to capture our three types of indicators. Women were asked about their opinions as follows: 1) "Do you think women should get leadership positions in the society"; 2) "Can you go to the doctor for treatment without permission"; 3) "Can you visit a relative, friend or neighbor without permission"; 4) "In your family, do you usually have the final say in making large household purchases"; 5) "In your family, do you usually have the final say in taking the children to the doctor." As Table 21 in the Appendix shows, women in households where there are returnees are more likely to experience negative impact for all outcomes compared to women in households with no migration experience. ${ }^{15}$ To quantify our results so far, Table 22 in the Appendix shows the predicted probabilities. First the three indices show significant difference in the

\footnotetext{
${ }^{15}$ In addition, we also test the robustness of our findings to a different matching age for the real price of crude oil in the selection into emigration equation. Specifically, we associate to each individual in our sample the historical real price of crude oil at the age of 24 , which is the standard age for the end of university education in Jordan. This may be an alternative age at which the average Jordanian enters in the labour market, and hence faces the choice between working within the country or migrating abroad. Table 23 in Appendix suggests again the strong robustness of our results.
} 
predicted values between women in returnee households relative to those in non-migrant households. Women in returnee households have lower self-perceived role of women (RWI) at 88 compared to 93 for women in non-migrants households. Women in Jordan tend to have low freedom of mobility, but the difference is stark with the two groups with women in non-migrants households having more freedom relative to almost no freedom for women in returnee households. Finally, DMPI, the self-perceived decision making power is 0.25 for women in returnee households and 0.35 for those in non-migrant households.

As a further robustness check, we use an alternative exclusion restriction for the emigration selection. We construct a proxy for the attractiveness of foreign labor markets when the individual was 20 years old, following see Tuccio et al. (2016). This measure of attractiveness is calculated as the relative GDP per capita growth rate of each possible destination relative to that of Jordan, weighted by the size of the diaspora in that destination, and then we use the most attractive destination for each potential migrant at age 20. ${ }^{16}$ The results using this alternative exclusion restrictions are presented in Table 24. Two important findings emerge: (i) the new exclusion restriction for the probability of emigration is statistically significant (although its explanatory power is slightly smaller than the one of historical oil prices); (ii) our coefficient of interest - i.e. return migrant - remains negative and significant throughout all specifications, consistently with our previous findings.

Concerning the role of women, 65 percent of the women in returnee households thought women should get leadership positions in the society compared to 87 percent in nonmigrant households. In terms of decision making, less than 0.5 percent of women in

\footnotetext{
${ }^{16}$ See Tuccio et al. (2016) for details on constructing this measure. It has to be noted that oil prices could be driving the differential GDP fluctuations.
} 
return migrant's households can make large household purchases decisions compared to 11 percent of women in non-migrant households. As far as freedom of mobility, having a returnee in the family reduces women's probability of going to the doctor without permission to 0.5 percent, whilst for women in non-migrant household 10 percent need permission. Similarly, women in returnee households are restricted in visiting relatives without permission (1 percent) compared to 9 percent among women living in non-migrant households. For taking children to doctor, women in returnee households have 12 percent probability of having the say on whether to take the children to the doctor, compared to 39 percent in non-migrant households. Overall, the results show that Jordan is a traditional society but there is a clear significant difference in women empowerment among those living in return migrant households versus those families who did not experience migration.

Summing up, we consistently find a negative impact of return migration on gender norms in Jordan. ${ }^{17}$ According to our hypothesis, returnees bring back home gender norms assimilated during their stay at receiving countries. ${ }^{18}$ Hence, to understand why the relationship between returnees and gender norms in Jordan seems to be negative, we need to focus on destinations and their gender norms. As previously mentioned, we restricted our analysis to migration towards the Arab region. Gender norms in Arab countries are overall discriminatory against women. A 2010 Freedom House report argues that women throughout the Middle East continue to face systematic inequality in both laws and social customs (Kelly (2010)). According to the same report, political and civil unrest in some regions have even hindered women's condition over the last decade. For example, gender-

\footnotetext{
${ }^{17}$ We have also checked the robustness of our findings differentiating between wives and daughters and all our results hold.

${ }^{18}$ Although it is plausible to assume that migration duration at destination affects the transfer of norms, we do not find any significant evidence of such a mechanism.
} 
based violence in Iraq worsened women's livelihoods by forcing them to stay home, away from education and employment.

However, even within the Arab region, countries have different degrees of traditional social gender norms. We exploit this heterogeneity in gender norms by defining countries on the basis of their degree of conservatism. In order to proxy for the underlying gender norms in practice in each country, we make use of the 2007 CIRI Human Rights Data Project, which includes two indices measuring the political and social rights that women have in each country (Cingranelli and Richards (2010)). ${ }^{19}$ Clearly, these rights can be interpreted as opportunities open to women rather than female outcomes (which is instead the case for other cross-country gender indices, such as the Global Gender Gap by WEF or the Gender Inequality Index by UNDP, including educational and employment dimensions as well). We therefore calculate the average of the two CIRI political and social indices, and distinguish destination countries between those having lower average values than Jordan and those with similar or greater values. ${ }^{20}$

Regardless of the weighting technique adopted and controlling for both selections into emigration and return migration, estimates confirm that, whilst migrants towards countries with similar level of conservatism do not matter, having a returnee from more conservative countries drives our finding of a significant and negative impact of return migration on the self-perceived role of women (Table 6). Results are similar using the Freedom of Mobility Index (FMI) or the Decision Making Power Index (DMPI) (see Tables 7 and 8

\footnotetext{
${ }^{19}$ Data are from 2007 since the indicator on women's social rights has been collected only in that year, but it is instead key for our analysis, as it measures several social norms such as women's right to equal inheritance, right to participate in social, cultural, and community activities, right to enter into marriage on a basis of equality with men, and so forth.

${ }^{20}$ Approximately 11 percent of the returnees in our sample lived in countries with more conservative gender norms than Jordan, which include: Bahrain, Egypt, Kuwait, Lebanon, Libya, Palestine, Qatar, Saudi Arabia, United Arab Emirates, and Yemen. Conversely, countries with similar gender norms than Jordan represents are: Algeria, Iraq, Morocco, Oman, Sudan, Syria, and Tunisia.
} 
respectively). ${ }^{21}$ This suggests that the impact of international migration on gender norms depends on the level of gender inequality in destination countries. In a different setting, Clingingsmith et al. (2009) studies the impact of the Hajj pilgrimage to Mecca which lasts for five days on Pakistani pilgrims' attitudes, and finds that Hajj leads to more favorable attitudes toward women, including greater acceptance of female education and employment. They argue that changes in attitudes are driven by exposure to and interaction with Hajjis from around the world. Hence, supporting our evidence that exposure to different social norms even if for a short period of time can have an impact, but in their case lead to favorable attitudes due to exposure to more equitable attitudes.

Although we control for emigration and return migration, another potential selection is the country of destination. Finding a suitable exclusion restriction that affects the emigration decision but not the migration destination (and vice versa) is challenging. It has to be noted that our focus here is on temporary emigration to other Arab countries where migration is indeed determined by wage differentials and tends to be demand driven. ${ }^{22}$ Moreover, our econometric specification controls for characteristics such as mother's education and consanguineous marriage, which are a proxy for the conservatism of the family, and hence partially take into account the gender norms of the migrant before moving abroad. We also look at the difference in means for these two variables for male returnees from more and less conservative destinations. We find no statistical difference between the likelihood of consanguineous marriage and maternal education of returnees from destinations with different levels of conservatism. Consequently this bias, if it exists,

\footnotetext{
${ }^{21}$ It is worth noting that returnees from less conservative countries do not have a statistically significant impact on gender norms of women in Jordan, in spite of representing a much larger proportion of return migrants in our sample. While this can in part be linked to relatively larger standard errors, such finding might also suggest that in a relatively conservative environment - such as Jordan - generating a shift towards more conservatism is easier than moving towards more liberal attitudes.

${ }^{22}$ See McKenzie et al. (2014) on how migration to the Gulf States is demand driven.
} 
is expected to be positive but small.

As a further robustness of our conservatism measure and findings, we use the share of the seats in lower and upper parliament held by women in 2010 based on UNDP data, relative to that in Jordan. The range of values is between 0.1 percent which is observed in Saudi Arabia and Qatar and almost 25 percent in Iraq, Sudan and Tunisia. In Jordan the share of seats held be women in parliament is 11 per cent. Since this is a continuous variable we normalize it with reference to Jordan. We find that the interaction between return migrant and this new measure to be positive as shown in Table 9; i.e. a there is a positive relationship between returnees from destinations where there are more females in parliament and women empowerment.

\subsection{Return migration and gender outcomes}

Our results so far show that return migration fosters the gender gap. In particular, conservative and very traditional views regarding women are perpetuated through migration. As shown, those gender norms are captured not only through female perceptions of their own roles, but also in their freedom of mobility and their decision making. In order for us to understand further the extent to which return migration affects gender inequalities, we examine several women's outcomes.

We use the same empirical strategy as before where we estimate multi- linear equation models in which we control for emigration and return migration to study the impact of return migration on our outcome of interest.

$$
F_{i}=\alpha_{0}+\alpha_{1} R_{i}+\alpha_{2} V_{i}+\epsilon_{i}
$$




$$
\begin{aligned}
& M_{k}=\beta_{0}+\beta_{1} O_{k}+\beta_{2} Z_{k}+\mu_{k} \\
& R_{k}=\gamma_{0}+\gamma_{1} S_{k}+\gamma_{2} C_{k}+n_{k}
\end{aligned}
$$

$F_{i}$ is the gender outcome of interest detailed below. $V_{i}$ are controls capturing the women's and households characteristics. As before, in equation $6 M_{k}$ is the probability of individual $k$ being an emigrant, whilst $O_{k}$ is the historical international oil price variable. Controls $Z_{k}$ for the potential migrants and their household. In the return migration equation $7, R_{k}$ is the probability of being a return migrant, $S_{k}$ represents the shock variable, and $C_{k}$ is controls related to the migrant. As before our methodology (CMP) allows us to estimate each equation on the appropriate sample.

The first outcome of interest, $F=1$, is female employment. Although women are on average highly educated, with more than 40 percent having at least a secondary degree, only 14 percent of them is formally employed (see Table 1). One of the main causes of this paradox lies in the existence of gender norms which set what is deemed acceptable for women, limiting their employment at full capacity. On the one hand, female limited geographical mobility restrict women's job opportunities, but also employers' perception and low demand for female workers create further hurdles to women's access to the labour market. Indeed, in a recent randomized control trial in Jordan, Groh et al. (2016) found that employers often express explicit preferences for male workers, since women may experience problems interacting with customers due to culture.

In order to test the hypothesis of a link between return migration and female em- 
ployment, we focus on female labour force participation which is preferred to the simple probability of employment since most women in Jordan tend to work for the public sector, and are willing to queue and stay unemployed for a while waiting a governmental job (Assaad et al. (2014a)). We also restrict our sample to 291 unmarried women, as Jordanian married women have very low participation rates (14 percent), and keeping them in the analysis would bias our estimates. ${ }^{23}$ In order to control for household income/wealth, we create an asset index, constructed as exogenously as possible by aggregating information about housing characteristics. Inspired by Filmer and Pritchett (2001), our asset index includes overall area and ownership of the accommodation, whether there is piped water, a bathroom, a fireplace/heater, water heating and whether the house is attached to the public sewage. ${ }^{24}$

Once controlling for both selections into emigration and return migration, Table 10 indeed shows that having a returnee in the household reduces the likelihood of unmarried women to be in the labour force (column 1). Distinguishing between returnees from more conservative destination countries (column 2) and returnees from countries with similar gender norms than Jordan (column 3) suggests the transfer of opposite norms.

As an important robustness check, we test whether having a return migrant in the household affects the probability of unmarried male members to be in the labour force. If our hypothesis of a transfer of social norms that discriminate against women from

\footnotetext{
${ }^{23}$ As stressed by Assaad et al. (2014a), discrimination against married women take place directly at the hiring level, since employers often assume that wives' responsibilities would prevent them from commitment at work, and hence they prefer to hire men and unmarried women. As a consequence, women themselves tend to stop looking for a job after marriage and withdraw from the labor force. See column 4 of Table 10 for results on married women.

${ }^{24}$ The JLMPS database also provides a proxy for household wealth, which is measured by aggregating several housing characteristics and appliances. Results are also robust to this alternative indicator of wealth and are available from the authors. For robustness we re-run all specifications in the previous section on gender norms controlling for the asset index. Results are comparable and available upon request.
} 
destination to origin country is correct, we would expect to find no significant result of the return migration variable on men. If, on the contrary, the coefficient turns out significant, it may be the result of some unobservables that our econometric strategy does not properly take into account. Remarkably, column 5 shows no significant relationship between having a returnee in the family and male labour force participation, corroborating our findings of a transfer of discriminatory gender norms.

Women's education is a key strategy for reducing poverty and contributing to economic development by improving the productive capacities of the labor force. Our second outcome, $F=2$, relates therefore to female education. We look at how women's education interacts with return migration. Although Jordan has overall relatively high female education levels, international migration may still affect the probability of a girl dropping out from school if her father has been exposed to highly conservative gender norms during his migration experience. Remarkably, in our dataset we are able to identify the likelihood of daughters leaving education due to customs and traditions. We condition here on girls who dropped out of school because of customs and traditions and end up with 90 girls. Although this is a small select sample, it still provides us with suggestive evidence on the impact of return migration on female outcomes.

Controlling again for wealth, column 1 in Table 11 suggests that returnees are more likely than non-migrant fathers to make their daughters drop-out from school due to patriarchal gender norms. In particular, column 2 shows that findings are driven by returnees from more conservative Arab destinations (whilst the coefficient of return migration from countries with similar gender norms than Jordan in column 3 is not significant). As a further robustness check, we replicate the analysis for sons (column 4). Returnee fathers 
do not appear to increase the likelihood of sons dropping-out of education because of traditional values, confirming our hypothesis of a migration-induced transfer of traditional gender norms.

A further socioeconomic dimension which is deeply interlocked with social norms is women's fertility (Munshi and Myaux (2006)). While at the aggregate level high fertility rates are detrimental to the economy, since they reduce available resources and jobs opportunities, at household level having numerous children is often associated with lower female empowerment, as mothers may not get further education or employment due to the large family size. The dependent variable in column 1 of Table 12 is hence the probability of having at least one child $(F=3)$.

Results suggest that wives with a returnee husband are more likely to be mothers. Column 2 shows the relationship between returnee husbands and the number of children $(F=4)$, which is instead a choice of the couple. A concern for this analysis may be that returnees have higher incomes and therefore can afford having more children. For this reasons, all presented specifications include our constructed asset index. All the results are robust to the inclusion of the different wealth indicators (ours and that provided directly by the JLMPS) and to the exclusion of a wealth proxy. ${ }^{25}$ Remarkably, the results show that returnees from more conservative countries have positive significant effect on fertility (column 3), while returnees from countries with similar gender norms to Jordan's do not appear to significantly modify left-behind members' social norms, even after controlling for income/wealth effect (column 4). To sum up, our findings show that return migration affect not only perception but also women's outcomes.

We conclude by quantifying the impact of return migration on the selected female out${ }^{25}$ Results are available from the authors. 
comes by calculating their predicted values for women with a returnee household member and women with no migration experience in the family. Table 13 the first column shows raw average, and the second column is the combined predicted probability for both groups (returnee and non-migrant household). Women in returnee households are 11 percent likely to be in the labour force compared to 25 percent likelihood among women in non-migrant households. Similarly, daughters in returnee households are 56 percent more likely to have dropped out of school because of traditional values compared to 11 percent for daughters in non-migrant households. Finally, wives of returnees are more likely not only to be mothers, but also to have 4.8 children compared to wives of stayers (3.8 children), controlling for income.

\section{Conclusions}

This paper studies the impact of return migration on the transfer of gender norms. We focus on the case of Jordan where female labour force participation is among the lowest in the world and where more than one household out of 10 have a returnee family member from other Arab countries. We construct several composite indices of female empowerment capturing (i) the self-perceived role of women, (ii) female freedom of mobility and (iii) women's decision making power, and use various weighting techniques.

Controlling for both selection into emigration and selection into return migration, our estimates show that women with a returnee in the household are more likely to have traditional gender norms than women in households with no migration experience. Similar findings are obtained when examining women's freedom of mobility and decision-making power. Our results are also robust to the use of different weighting techniques for the con- 
struction of the female empowerment composite index, such as Multiple Correspondence Analysis (MCA), Principal Component Analysis (PCA) and equal weights.

Interestingly, we find that the results are driven by returnees from more conservative Arab countries, which indeed bear great level of gender inequalities. This confirms our initial hypothesis of a transfer of gender norms through return migration. However, in this case return migration does not promote better institutions at home through the transfer of norms from destination countries, but encourages more traditional gender norms if the returnee has lived in a highly conservative destination.

Concerning the role of women, 65 percent of the women in returnee households think women should get leadership positions in the society compared to 87 percent in nonmigrant households. In terms of decision making, less than 0.5 percent of women in return migrant's households can make large household purchases decisions compared to 11 percent of women in non-migrant households. As far as freedom of mobility, women in returnee households have little freedom of mobility (needing permission to go to the doctor or visit relatives), whilst for women in non-migrant households, 10 percent do not need permission. Furthermore, our results show that the impact of return migration goes beyond perception and negatively affect economy-wide women's outcomes as well. For instance, women with a returnee family member have an 11 percent probability of participating in the labour force compared to women in non-migrant households who have 25 per cent, as well as they are more likely to drop out of school for traditional values, and have more greater fertility rates.

Clearly, the migration-induced transfer of traditional gender norms is not an issue limited to Jordan only. More than 17.5 million foreigners lived and worked in Gulf countries 
in 2010, representing a staggering 43 percent of the overall GCC population (Fargues (2011)). Bahrain, Kuwait, Oman, Qatar, Saudi Arabia and the United Arab Emirates are considered to have the highest proportion of migrant workers in the world. In 1975 immigrants in the Gulf were around 940,000, becoming 8,240,000 in 1990, and more than doubling by 2010 . It is therefore extremely timely to deepen our knowledge of the consequences that migration to conservative destinations bear on origin countries. 


\section{Bibliography}

Alesina, A., Giuliano, P., Nunn, N., 2013. On the origins of gender roles: Women and the plough. The Quarterly Journal of Economics 128, 469-530.

Antman, F.M., 2015. Gender discrimination in the allocation of migrant household resources. Journal of Population Economics 28, 565-592.

Ashraf, N., 2009. Spousal control and intra-household decision making: An experimental study in the philippines. American Economic Review , 1245-1277.

Assaad, R., Hendy, R., Yassine, C., 2014a. Gender and the jordanian labor market. In Assaad, R. (Ed.), The Jordanian Labour Market in the New Millennium, Chapter 4. Oxford University Press .

Assaad, R., Nazier, H., Ramadan, R., 2014b. Individual and households determinants of women empowerment: Application to the case of egypt. ERF Working Paper No. 867 .

Barsbai, T., Rapoport, H., Steinmayr, A., Trebesch, C., 2017. The effect of labor migration on the diffusion of democracy: Evidence from a former soviet republic. American Economic Journal: Applied Economics forthcoming.

Batista, C., Vicente, P.C., 2011. Do migrants improve governance at home? evidence from a voting experiment. The World Bank Economic Review 25, 77-104.

Beaman, L., Chattopadhyay, R., Duflo, E., Pande, R., Topalova, P., 2009. Powerful women: Does exposure reduce bias? The Quarterly Journal of Economics 124, 14971540. 
Beine, M., Docquier, F., Schiff, M., 2013. International migration, transfers of norms and home country fertility. Canadian Journal of Economics 46, 1406-1430.

Bertoli, S., Marchetta, F., 2015. Bringing it all back home: Return migration and fertility choices. World Development 65, 27-40.

Booysen, F., Van Der Berg, S., Burger, R., Maltitz, M.v., Rand, G.d., 2008. Using an asset index to assess trends in poverty in seven sub-saharan african countries. World Development 36, 1113-1130.

Chauvet, L., Mercier, M., 2014. Do return migrants transfer political norms to their origin country? evidence from mali. Journal of Comparative Economics 42, 630-651.

Cingranelli, D.L., Richards, D.L., 2010. The cingranelli and richards (ciri) human rights data project. Human Rights Quarterly 32, 401-424.

Clingingsmith, D., Khwaja, A.I., Kremer, M., 2009. Estimating the impact of the hajj: Religion and tolerance in islam's global gathering. The Quarterly Journal of Economics $124,1133-1170$.

David, A., Marouani, M.A., 2013. The labor mobility-employment nexus: A general equilibrium analysis of jordan. ERF Working Paper No. 824 .

De Haas, H., Van Rooij, A., 2010. Migration as emancipation? the impact of internal and international migration on the position of women left behind in rural morocco. Oxford Development Studies 38, 43-62.

Dhar, D., Jain, T., Jayachandran, S., 2015. Intergenerational transmission of gender attitudes: Evidence from india. NBER Working Paper No. 21429 . 
Duflo, E., 2012. Women empowerment and economic development. Journal of Economic Literature 50, 1051-79.

Fargues, P., 2011. Immigration without inclusion: Non-nationals in nation-building in the gulf states. Asian and Pacific Migration Journal 20, 273-292.

Ferrant, G., 2014. The multidimensional gender inequalities index (mgii): A descriptive analysis of gender inequalities using mca. Social Indicators Research 115, 653-690.

Ferrant, G., Tuccio, M., 2015. South-south migration and discrimination against women in social institutions: A two-way relationship. World Development 72, 240-254.

Field, E., Jayachandran, S., Pande, R., 2010. Do traditional institutions constrain female entrepreneurship? a field experiment on business training in india. American Economic Review , 125-129.

Filmer, D., Pritchett, L.H., 2001. Estimating wealth effects without expenditure data or tears: An application to educational enrollments in states of india. Demography 38, $115-132$.

Groh, M., Krishnan, N., McKenzie, D., Vishwanath, T., 2016. Do wage subsidies provide a stepping-stone to employment for recent college graduates? evidence from a randomized experiment in jordan. Review of Economics and Statistics 98, 488-502.

Kelly, S., 2010. Women's Rights in the Middle East and North Africa. New York: Freedom House.

Lodigiani, E., Salomone, S., 2012. Migration-induced transfers of norms. the case of female political empowerment. IRES Discussion Papers 2012-1 . 
McKenzie, D., Theoharides, C., Yang, D., 2014. Distortions in the international migrant labor market: Evidence from filipino migration and wage responses to destination country economic shocks. American Economic Journal: Applied Economics 6, 49-75.

Meyersson, E., 2014. Islamic rule and the empowerment of the poor and pious. Econometrica 82, 229-269.

Munshi, K., Myaux, J., 2006. Social norms and the fertility transition. Journal of Development Economics 80, 1-38.

OAMDI, 2016. Labor Market Panel Surveys (LMPS), http://erf.org.eg/data-portal/. Version 2.0 of Licensed Data Files; JLMPS 2010. Cairo: Economic Research Forum (ERF).

OECD, 2014. Social Institutions \& Gender Index - Jordan. Available at: genderindex.org/sites/default/files/datasheets/JO.pdf (accessed 17 April 2017).

Roodman, D., 2011. Estimating fully observed recursive mixed-process models with cmp. Stata Journal 11(2), 159-206.

Spilimbergo, A., 2009. Democracy and foreign education. American Economic Review , $528-543$.

Tuccio, M., Wahba, J., Hamdouch, B., 2016. International migration: Driver of political and social change? IZA Discussion Paper No. 9794 .

Wahba, J., 2014. Immigration, emigration, and the labor market in jordan. In Assaad, R. (Ed.), The Jordanian Labour Market in the New Millennium, Chapter 6. Oxford University Press . 
Wahba, J., 2015. Selection, selection, selection: The impact of return migration. Journal of Population Economics 28, 535-563.

Wahba, J., Zenou, Y., 2012. Out of sight, out of mind: Migration, entrepreneurship and social capital. Regional Science and Urban Economics 42, 890-903.

World Bank, 2005. The economic advancement of women in Jordan: A country gender assessment. Washington, DC: The World Bank.

Xu, Z., Ratha, D., 2008. Migration and remittances factbook 2008. Washington, DC: The World Bank. 
Table 1: Characteristics of women in returnee and non-migrant households

\begin{tabular}{|c|c|c|c|c|c|c|}
\hline & Without migrant & With returnee & t-Test & $\begin{array}{l}\text { With returnee from more } \\
\text { conservative countries }\end{array}$ & $\begin{array}{l}\text { With returnee from less } \\
\text { conservative countries }\end{array}$ & t-Test \\
\hline Employment status & 0.14 & 0.11 & $(2.05)^{*}$ & 0.11 & 0.15 & $(-1.30)$ \\
\hline Less than basic education & 0.24 & 0.20 & $(2.69)^{* *}$ & 0.20 & 0.13 & $(1.72)$ \\
\hline Basic education & 0.36 & 0.30 & $(2.93)^{* *}$ & 0.29 & 0.38 & $(-1.83)$ \\
\hline Secondary education & 0.16 & 0.21 & $(-3.57)^{* * *}$ & 0.21 & 0.19 & $(0.53)$ \\
\hline Post-secondary education & 0.24 & 0.29 & $(-2.74)^{* *}$ & 0.29 & 0.30 & $(-0.13)$ \\
\hline Married & 0.92 & 0.91 & $(1.83)$ & 0.90 & 0.94 & $(-1.39)$ \\
\hline Consanguinity & 0.36 & 0.31 & $(3.12)^{* *}$ & 0.32 & 0.25 & $(1.40)$ \\
\hline Rural areas & 0.33 & 0.09 & $(13.78) * * *$ & 0.09 & 0.13 & $(-1.52)$ \\
\hline Age & 36.5 & 40.1 & $(-9.21)^{* * *}$ & 40.4 & 38.2 & $(1.93)$ \\
\hline Children & 0.92 & 0.92 & $(-0.29)$ & 0.92 & 0.94 & $(-0.79)$ \\
\hline Mother's education & 1.49 & 1.70 & $(-5.72)^{* * *}$ & 1.66 & 1.92 & $(-2.23)^{*}$ \\
\hline ROWI & 0.92 & 0.92 & $(2.13)^{*}$ & 0.92 & 0.91 & $(0.14)$ \\
\hline FMI & 0.06 & 0.07 & $(-1.47)$ & 0.07 & 0.04 & $(1.11)$ \\
\hline DMPI & 0.35 & 0.38 & $(-1.77)$ & 0.39 & 0.33 & $(1.49)$ \\
\hline$N$ & 3260 & 838 & & 733 & 105 & \\
\hline
\end{tabular}


Figure 1: Emigrants by year and historical real oil price

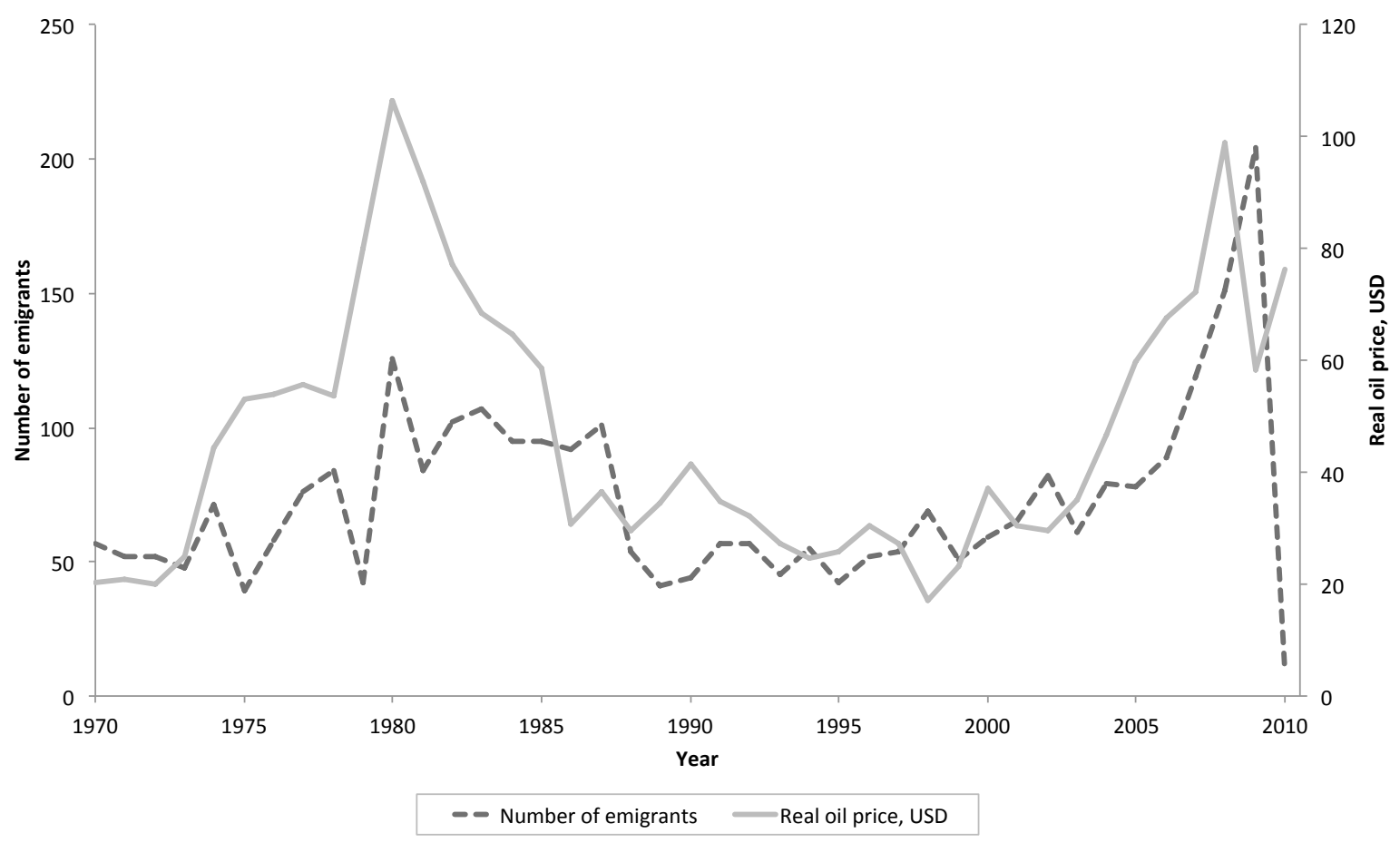


Figure 2: Return migrants by year and historical real oil price

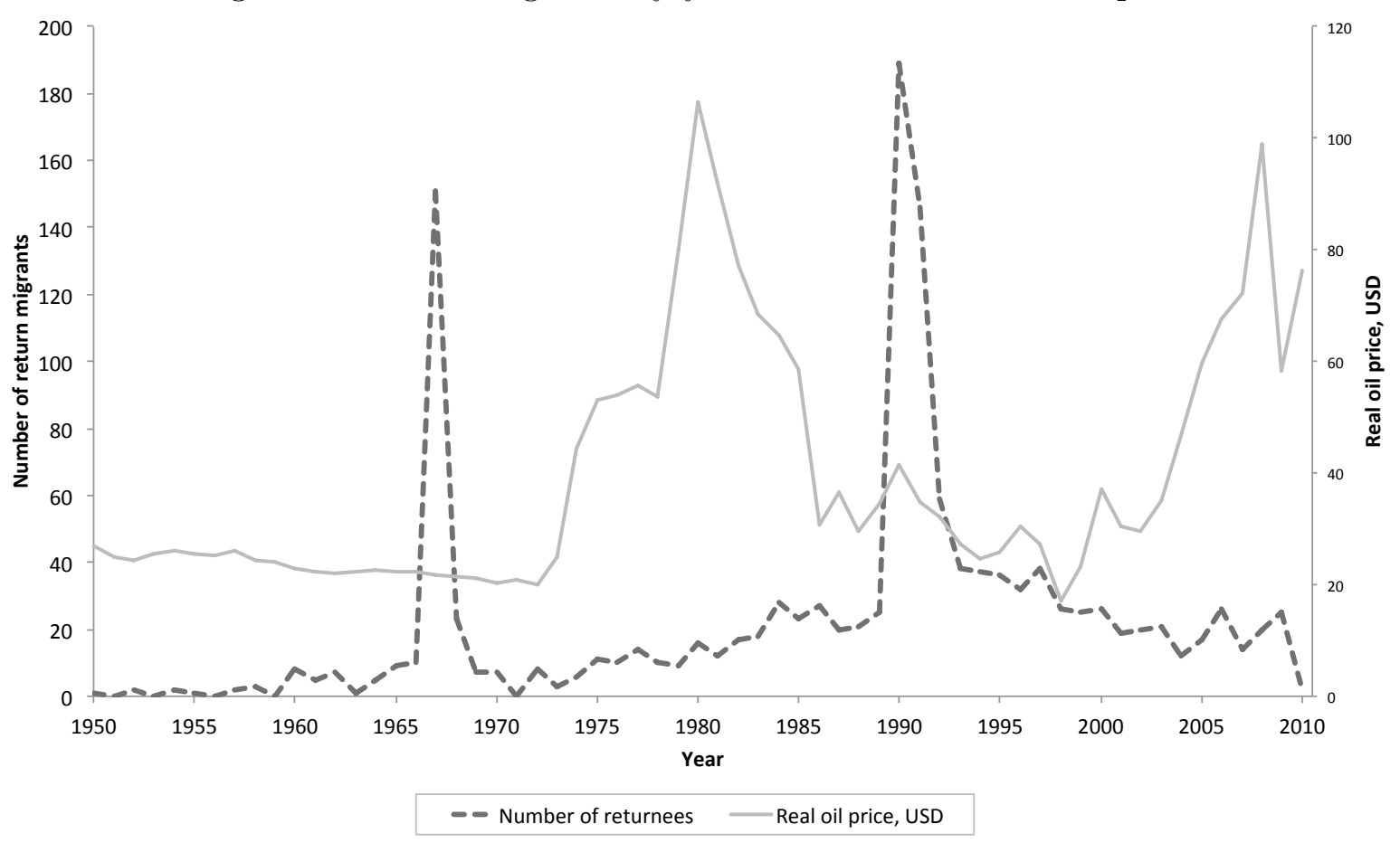


Figure 3: Year of migration and migration duration

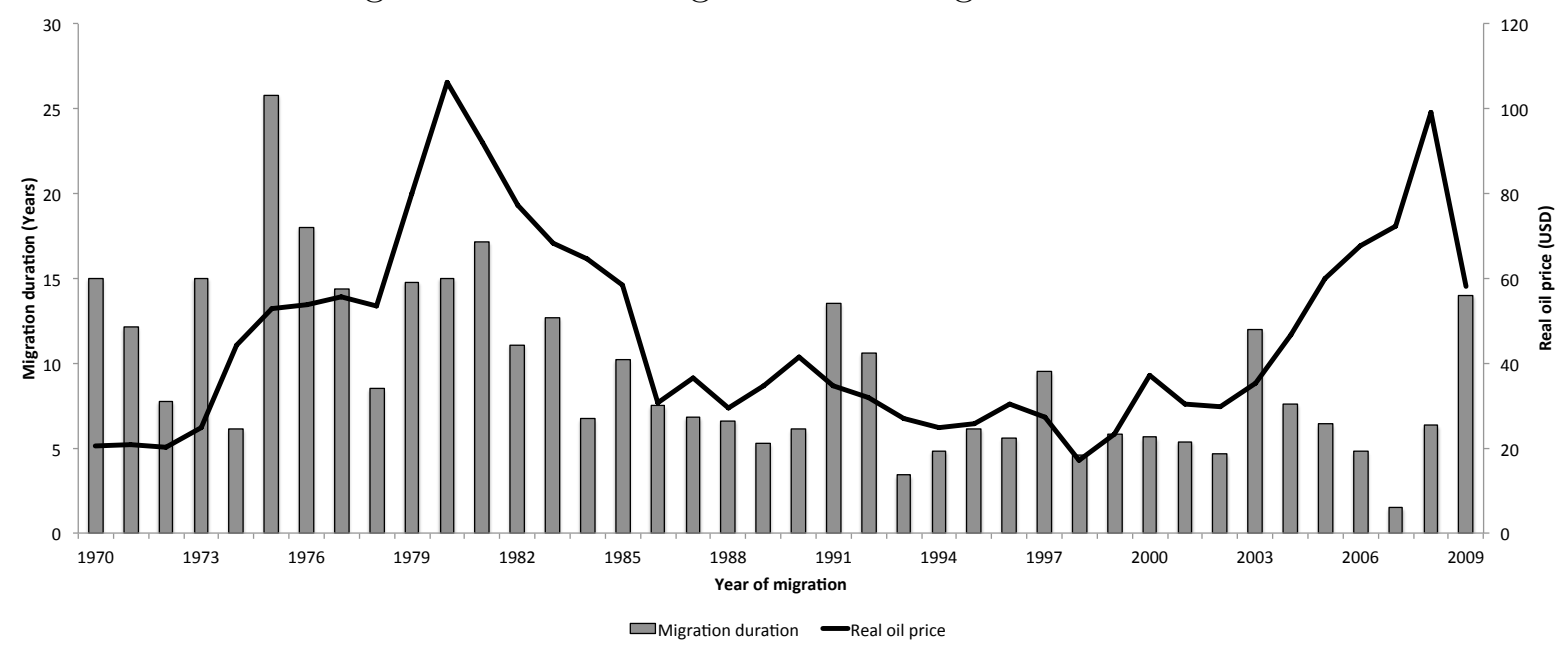


Figure 4: Emigrants by year and shocks

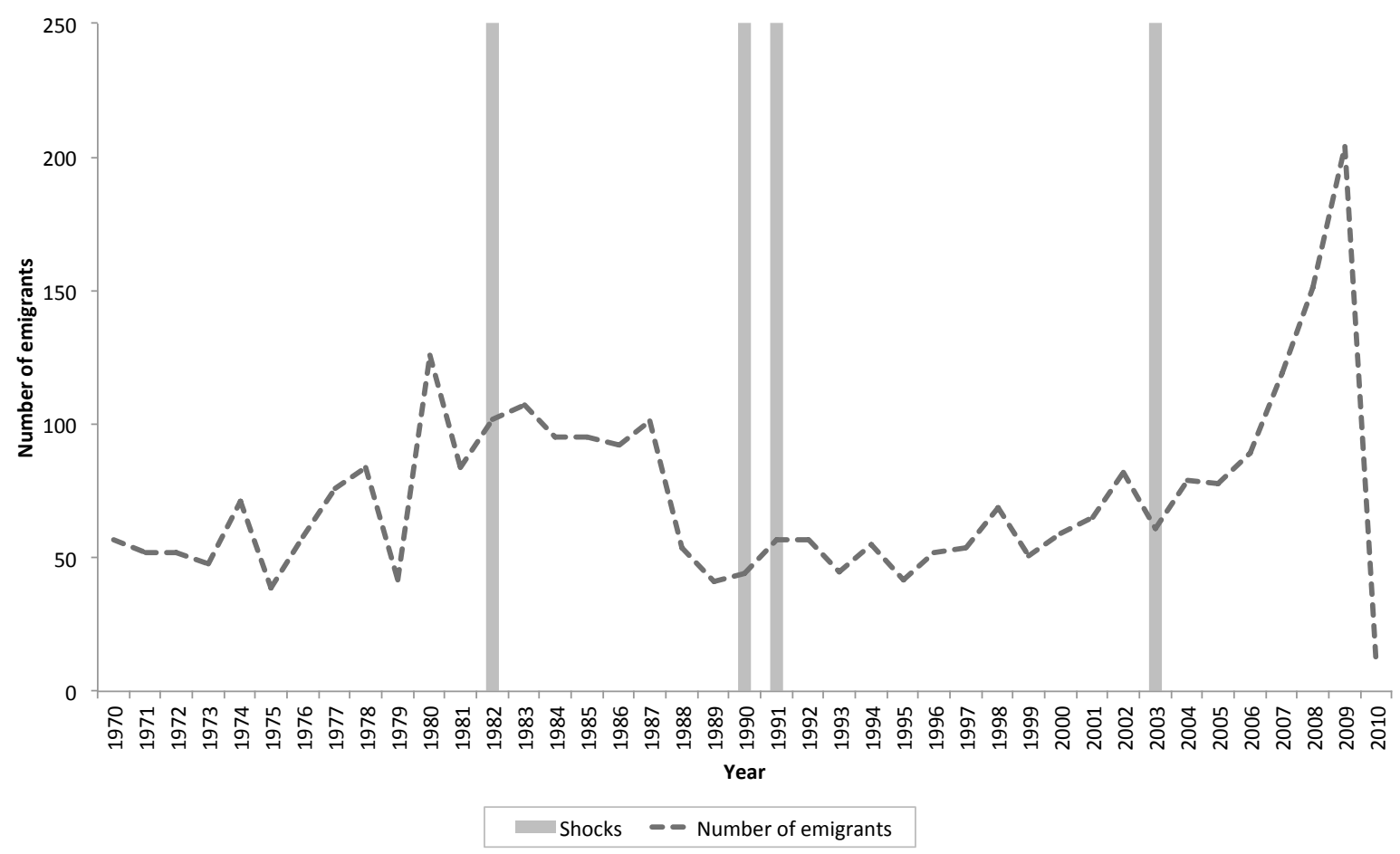


Table 2: Return migration and the Role of Women Index (RWI)

\begin{tabular}{|c|c|c|c|}
\hline & (1) & $(2)$ & (3) \\
\hline \multicolumn{4}{|l|}{$R W I$} \\
\hline Return migrant & $\begin{array}{l}-0.005 \\
(0.005)\end{array}$ & $\begin{array}{l}-0.051 \\
(0.037)\end{array}$ & $\begin{array}{c}-0.062 \\
(0.030)^{* *}\end{array}$ \\
\hline Employment status & $\begin{array}{c}0.020 \\
(0.004)^{* * *}\end{array}$ & $\begin{array}{c}0.023 \\
(0.005)^{* * *}\end{array}$ & $\begin{array}{c}0.022 \\
(0.005)^{* * *}\end{array}$ \\
\hline Basic education & $\begin{array}{c}0.011 \\
(0.006)\end{array}$ & $\begin{array}{c}0.015 \\
(0.007)^{* *}\end{array}$ & $\begin{array}{c}0.017 \\
(0.007)^{* *}\end{array}$ \\
\hline Secondary education & $\begin{array}{c}0.020 \\
(0.008)^{* * *}\end{array}$ & $\begin{array}{c}0.029 \\
(0.010)^{* * *}\end{array}$ & $\begin{array}{c}0.029 \\
(0.009)^{* * *}\end{array}$ \\
\hline Post-secondary education & $\begin{array}{c}0.028 \\
(0.006)^{* * *}\end{array}$ & $\begin{array}{c}0.039 \\
(0.011)^{* * *}\end{array}$ & $\begin{array}{c}0.050 \\
(0.013)^{* * *}\end{array}$ \\
\hline Married & $\begin{array}{l}-0.008 \\
(0.009)\end{array}$ & $\begin{array}{l}-0.008 \\
(0.009)\end{array}$ & $\begin{array}{l}-0.008 \\
(0.009)\end{array}$ \\
\hline Consanguineous marriage & $\begin{array}{c}0.002 \\
(0.004)\end{array}$ & $\begin{array}{c}0.002 \\
(0.004)\end{array}$ & $\begin{array}{c}0.002 \\
(0.004)\end{array}$ \\
\hline Rural area & $\begin{array}{c}0.002 \\
(0.004)\end{array}$ & $\begin{array}{c}0.002 \\
(0.004)\end{array}$ & $\begin{array}{c}0.003 \\
(0.004)\end{array}$ \\
\hline Age & $\begin{array}{c}0.003 \\
(0.001)^{* *}\end{array}$ & $\begin{array}{c}0.003 \\
(0.001)^{* *}\end{array}$ & $\begin{array}{c}0.003 \\
(0.002)^{* *}\end{array}$ \\
\hline Age squared & $\begin{array}{l}-0.003 \\
(0.002)\end{array}$ & $\begin{array}{l}-0.003 \\
(0.002)\end{array}$ & $\begin{array}{c}-0.004 \\
(0.002)^{*}\end{array}$ \\
\hline Children & $\begin{array}{c}0.011 \\
(0.008)\end{array}$ & $\begin{array}{c}0.012 \\
(0.008)\end{array}$ & $\begin{array}{c}0.012 \\
(0.008)\end{array}$ \\
\hline Mother's education & $\begin{array}{c}0.004 \\
(0.002)^{* *}\end{array}$ & $\begin{array}{c}0.004 \\
(0.002)^{* *}\end{array}$ & $\begin{array}{c}0.004 \\
(0.002)^{* *}\end{array}$ \\
\hline \multicolumn{4}{|l|}{ Probability of Emigration } \\
\hline Oil price & & $\begin{array}{c}0.002 \\
(0.000)^{* * *}\end{array}$ & $\begin{array}{c}0.001 \\
(0.000)^{* * *}\end{array}$ \\
\hline \multicolumn{4}{|l|}{ Probability of Return Migration } \\
\hline Shocks & & & $\begin{array}{c}0.148 \\
(0.009)^{* * *} \\
\end{array}$ \\
\hline sigma_1 & & $\begin{array}{c}-0.835 \\
(0.005)^{* * *}\end{array}$ & $\begin{array}{c}-0.874 \\
(0.006)^{* * *}\end{array}$ \\
\hline sigma_2 & & & $\begin{array}{c}-1.100 \\
(0.014)^{* * *}\end{array}$ \\
\hline rho_12 & & $\begin{array}{c}0.207 \\
(0.161)\end{array}$ & $\begin{array}{c}0.222 \\
(0.122)^{*}\end{array}$ \\
\hline rho_13 & & & $\begin{array}{c}0.223 \\
(0.103)^{* *}\end{array}$ \\
\hline rho $\_23$ & & & $\begin{array}{c}1.388 \\
(0.037)^{* * *}\end{array}$ \\
\hline $\mathrm{N}$ & 4,098 & 4,098 & 4,098 \\
\hline
\end{tabular}

Notes. (I) All specifications are weighted by the sampling weights provided in the dataset, with robust standard errors. (II) The selection equations are based on full sample of 13,943 individuals. (III) Data source: JLMPS, 2010. 
Table 3: The Role of Women Index using different weighting techniques

\begin{tabular}{lccc}
\hline & $\mathbf{( 1 )}$ & $\mathbf{( 2 )}$ & $\mathbf{( 3 )}$ \\
\hline $\boldsymbol{R W I}$ & $\mathbf{m c a}$ & $\boldsymbol{p c a}$ & $\boldsymbol{e q u a l}$ \\
Return migrant & -0.062 & -0.085 & -0.089 \\
& $(0.030)^{* *}$ & $(0.033)^{* *}$ & $(0.038)^{* *}$ \\
\hline Probability of Emigration & & & \\
Oil price & 0.001 & 0.001 & 0.001 \\
& $(0.000)^{* * *}$ & $(0.000)^{* * *}$ & $(0.000)^{* * *}$ \\
\hline Probability of Return Migration & & & \\
Shocks & 0.148 & 0.148 & 0.148 \\
& $(0.009)^{* * *}$ & $(0.009)^{* * *}$ & $(0.009)^{* * *}$ \\
\hline sigma_1 & -0.874 & -0.874 & -0.874 \\
& $(0.006)^{* * *}$ & $(0.006)^{* * *}$ & $(0.006)^{* * *}$ \\
sigma_2 & -1.100 & -1.100 & -1.100 \\
& $(0.014)^{* * *}$ & $(0.014)^{* * *}$ & $(0.014)^{* * *}$ \\
rho_12 & 0.222 & 0.262 & 0.218 \\
& $(0.122)^{*}$ & $(0.120)^{* *}$ & $(0.107)^{* *}$ \\
rho_13 & 0.223 & 0.252 & 0.210 \\
& $(0.103)^{* *}$ & $(0.102)^{* *}$ & $(0.094)^{* *}$ \\
rho_23 & 1.388 & 1.388 & 1.388 \\
& $(0.037)^{* * *}$ & $(0.037)^{* * *}$ & $(0.037)^{* * *}$ \\
\hline $\mathrm{N}$ & 4,098 & 4,098 & 4,098 \\
\hline
\end{tabular}

Notes. (I) All specifications are weighted by the sampling weights provided in the dataset, with robust standard errors. (II) The selection equations are based on full sample of 13,943 individuals. (III) Data source: JLMPS, 2010. 
Table 4: Return migration and the Freedom of Mobility Index (FMI)

\begin{tabular}{|c|c|c|c|}
\hline & (1) & $(2)$ & $(3)$ \\
\hline$F M I$ & $m c a$ & pca & equal \\
\hline \multirow[t]{2}{*}{ Return migrant } & -0.131 & -0.140 & -0.131 \\
\hline & $(0.045)^{* * *}$ & $(0.043)^{* * *}$ & $(0.045) * * *$ \\
\hline \multicolumn{4}{|c|}{ Probability of Emigration } \\
\hline \multirow[t]{2}{*}{ Oil price } & 0.001 & 0.001 & 0.001 \\
\hline & $(0.000)^{* * *}$ & $(0.000) * * *$ & $(0.000) * * *$ \\
\hline \multicolumn{4}{|c|}{ Probability of Return Migration } \\
\hline \multirow[t]{2}{*}{ Shocks } & 0.148 & 0.148 & 0.148 \\
\hline & $(0.009)^{* * *}$ & $(0.009)^{* * *}$ & $(0.009)^{* * *}$ \\
\hline \multirow[t]{2}{*}{ sigma_1 } & -0.899 & -0.899 & -0.899 \\
\hline & $(0.006) * * *$ & $(0.006)^{* * *}$ & $(0.006)^{* * *}$ \\
\hline \multirow[t]{2}{*}{ sigma_2 } & -1.138 & -1.138 & -1.138 \\
\hline & $(0.015)^{* * *}$ & $(0.015)^{* * *}$ & $(0.015)^{* * *}$ \\
\hline \multirow[t]{2}{*}{ rho_12 } & 0.304 & 0.336 & 0.303 \\
\hline & $(0.095)^{* * *}$ & $(0.095)^{* * *}$ & $(0.095) * * *$ \\
\hline \multirow[t]{2}{*}{ rho_13 } & 0.282 & 0.318 & 0.282 \\
\hline & $(0.092)^{* * *}$ & $(0.092)^{* * *}$ & $(0.092)^{* * *}$ \\
\hline \multirow[t]{2}{*}{ rho_23 } & 1.387 & 1.387 & 1.387 \\
\hline & $(0.037)^{* * *}$ & $(0.037)^{* * *}$ & $(0.037)^{* * *}$ \\
\hline $\mathrm{N}$ & 4,098 & 4,098 & 4,098 \\
\hline
\end{tabular}

Notes. (I) All specifications are weighted by the sampling weights provided in the dataset, with robust standard errors. (II) The selection equations are based on full sample of 13,943 individuals. (III) Data source: JLMPS, 2010. 
Table 5: Return migration and the Decision Making Power Index (DMPI)

\begin{tabular}{lccc}
\hline & $\mathbf{( 1 )}$ & $\mathbf{( 2 )}$ & $\mathbf{( 3 )}$ \\
\hline DMPI & $\mathbf{m c a}$ & $\boldsymbol{p c a}$ & equal \\
Return migrant & -0.153 & -0.151 & -0.148 \\
& $(0.082)^{*}$ & $(0.066)^{* *}$ & $(0.088)^{*}$ \\
\hline Probability of Emigration & & & \\
Oil price & 0.001 & 0.001 & 0.001 \\
& $(0.000)^{* * *}$ & $(0.000)^{* * *}$ & $(0.000)^{* * *}$ \\
\hline Probability of Return Migration & & & \\
Shocks & 0.001 & 0.001 & 0.001 \\
& $(0.000)^{* * *}$ & $(0.000)^{* * *}$ & $(0.000)^{* * *}$ \\
\hline sigma_1 & -0.953 & -0.953 & -0.952 \\
& $(0.006)^{* * *}$ & $(0.006)^{* * *}$ & $(0.006)^{* * *}$ \\
sigma_2 & -1.207 & -1.207 & -1.207 \\
& $(0.015)^{* * *}$ & $(0.015)^{* * *}$ & $(0.015)^{* * *}$ \\
rho_12 & 0.243 & 0.246 & 0.238 \\
& $(0.149)$ & $(0.139)^{*}$ & $(0.155)$ \\
rho_13 & 0.237 & 0.263 & 0.232 \\
& $(0.135)^{*}$ & $(0.133)^{* *}$ & $(0.140)^{*}$ \\
rho_23 & 1.388 & 1.388 & 1.388 \\
& $(0.037)^{* * *}$ & $(0.037)^{* * *}$ & $(0.037)^{* * *}$ \\
\hline $\mathrm{N}$ & 3,773 & 3,773 & 3,773 \\
\hline
\end{tabular}

Notes. (I) All specifications are weighted by the sampling weights provided in the dataset, with robust standard errors. (II) The selection equations are based on full sample of 13,943 individuals, while the outcome equation is restricted to married women. (III) Data source: JLMPS, 2010. 
Table 6: Return migration by destination and the Role of Women Index (RWI)

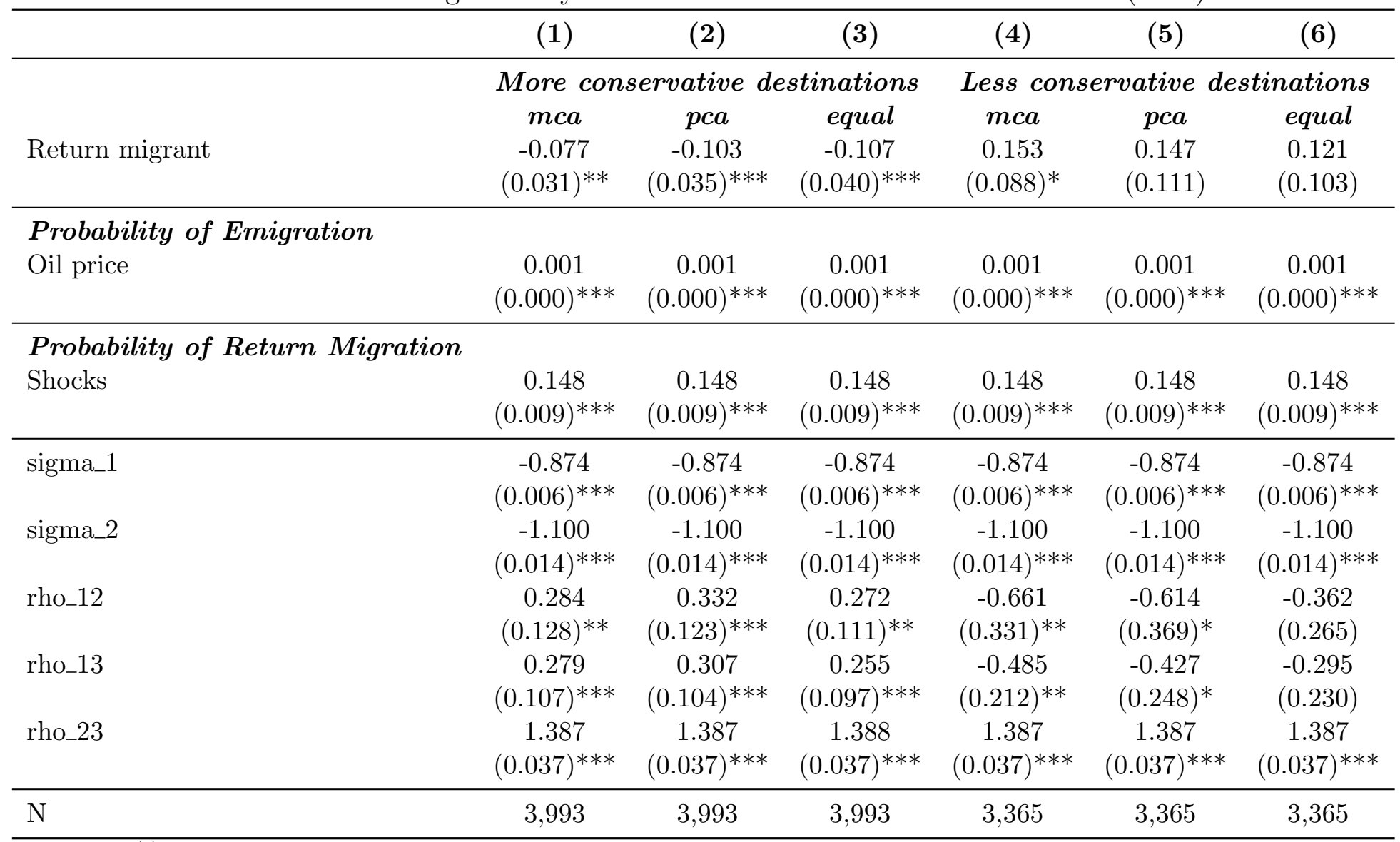

Notes. (I) All specifications are weighted by the sampling weights provided in the dataset, with robust standard errors. (II) The selection equations are based on full sample of 13,943 individuals. (III) Data source: JLMPS, 2010. 
Table 7: Return migration by destination and the Freedom of Mobility Index (FMI)

\begin{tabular}{lcccccc}
\hline & $(\mathbf{1})$ & $(\mathbf{2})$ & $\mathbf{( 3 )}$ & $\mathbf{( 4 )}$ & $\mathbf{( 5 )}$ & $\mathbf{( 6 )}$ \\
\hline & More conservative & destinations & \multicolumn{2}{c}{ Less conservative destinations } \\
& $\mathbf{m c a}$ & $\boldsymbol{p c a}$ & equal & mca & pca & equal \\
Return migrant & -0.129 & -0.137 & -0.129 & -0.133 & -0.142 & -0.131 \\
& $(0.046)^{* * *}$ & $(0.043)^{* * *}$ & $(0.046)^{* * *}$ & $(0.098)$ & $(0.093)$ & $(0.099)$ \\
\hline Probability of Emigration & & & & & & \\
Oil price & 0.001 & 0.001 & 0.001 & 0.001 & 0.001 & 0.001 \\
& $(0.000)^{* * *}$ & $(0.000)^{* * *}$ & $(0.000)^{* * *}$ & $(0.000)^{* * *}$ & $(0.000)^{* * *}$ & $(0.000)^{* * *}$ \\
\hline Probability of Return Migration & & & & & & \\
Shocks & 0.148 & 0.148 & 0.148 & 0.148 & 0.148 & 0.148 \\
& $(0.009)^{* * *}$ & $(0.009)^{* * *}$ & $(0.009)^{* * *}$ & $(0.009)^{* * *}$ & $(0.009)^{* * *}$ & $(0.009)^{* * *}$ \\
\hline sigma_1 & -0.897 & -0.897 & -0.897 & -0.882 & -0.882 & -0.882 \\
& $(0.006)^{* * *}$ & $(0.006)^{* * *}$ & $(0.006)^{* * *}$ & $(0.006)^{* * *}$ & $(0.006)^{* * *}$ & $(0.006)^{* * *}$ \\
sigma_2 & -1.135 & -1.136 & -1.135 & -1.114 & -1.114 & -1.114 \\
& $(0.015)^{* * *}$ & $(0.015)^{* * *}$ & $(0.015)^{* * *}$ & $(0.015)^{* * *}$ & $(0.015)^{* * *}$ & $(0.015)^{* * *}$ \\
rho_12 & 0.298 & 0.328 & 0.298 & 0.270 & 0.315 & 0.267 \\
& $(0.096)^{* * *}$ & $(0.096)^{* * *}$ & $(0.096)^{* * *}$ & $(0.236)$ & $(0.242)$ & $(0.236)$ \\
rho_13 & 0.289 & 0.324 & 0.289 & 0.250 & 0.289 & 0.246 \\
& $(0.097)^{* * *}$ & $(0.097)^{* * *}$ & $(0.097)^{* * *}$ & $(0.222)$ & $(0.224)$ & $(0.223)$ \\
rho_23 & 1.387 & 1.387 & 1.387 & 1.388 & 1.388 & 1.388 \\
& $(0.037)^{* * *}$ & $(0.037)^{* * *}$ & $(0.037)^{* * *}$ & $(0.037)^{* * *}$ & $(0.037)^{* * *}$ & $(0.037)^{* * *}$ \\
\hline $\mathrm{N}$ & 3,993 & 3,993 & 3,993 & 3,365 & 3,365 & 3,365 \\
\hline
\end{tabular}

Notes. (I) All specifications are weighted by the sampling weights provided in the dataset, with robust standard errors. (II) The selection equations are based on full sample of 13,943 individuals. (III) Data source: JLMPS, 2010. 
Table 8: Return migration by destination and the Decision Making Power Index (DMPI)

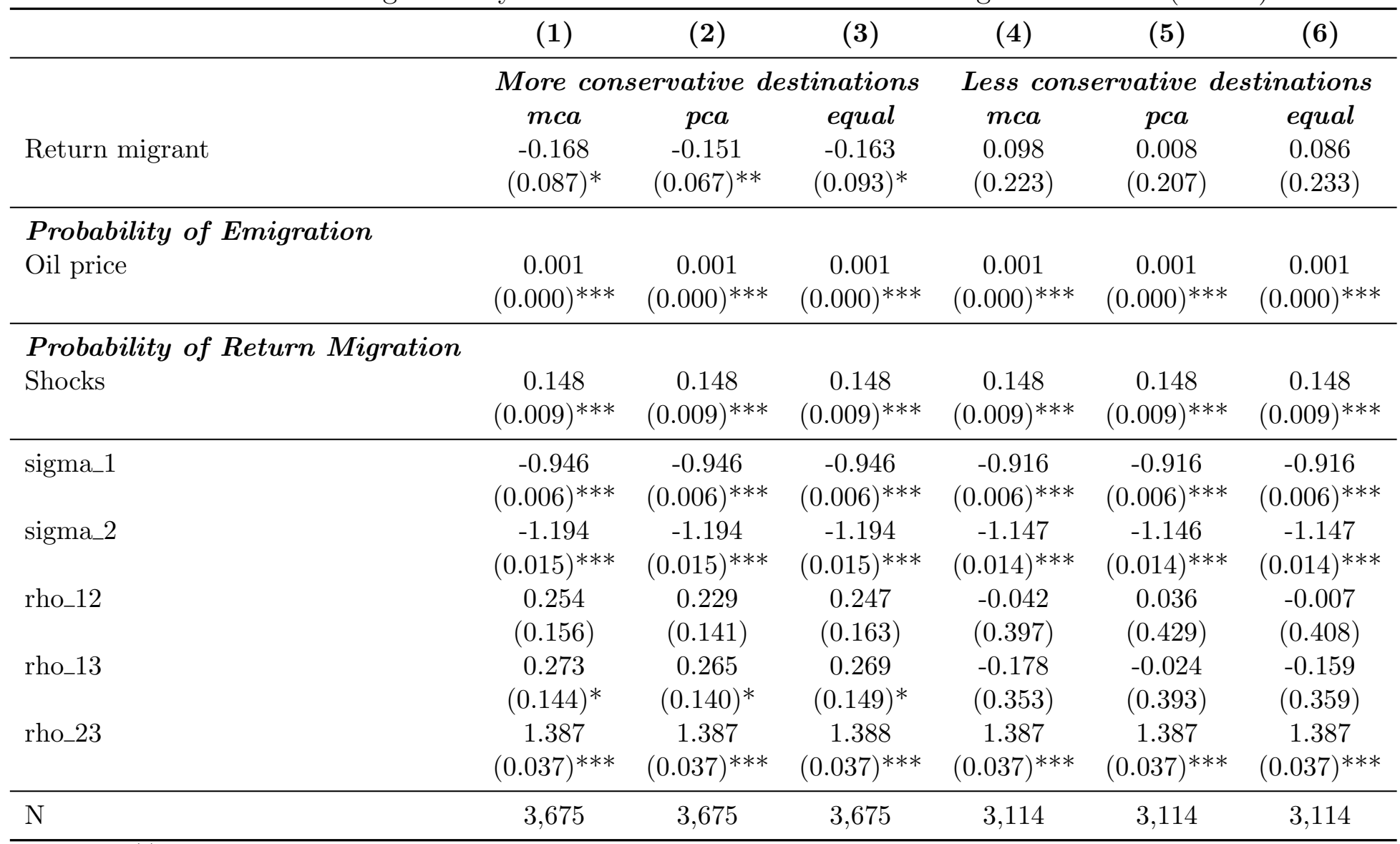

Notes. (I) All specifications are weighted by the sampling weights provided in the dataset, with robust standard errors.

(II) The selection equations are based on full sample of 13,943 individuals. (III) Data source: JLMPS, 2010. 
Table 9: Return migration and gender norms - Different exclusion restriction

\begin{tabular}{|c|c|c|c|c|}
\hline & (1) & (2) & (3) & $(4)$ \\
\hline & \multicolumn{2}{|c|}{$R W I$} & \multicolumn{2}{|c|}{$F M I$} \\
\hline & $m c a$ & equal & $m c a$ & equal \\
\hline \multirow{2}{*}{ Return Migrant*Seats in parliament (female \%) } & 0.0002 & 0.0003 & 0.0005 & 0.0005 \\
\hline & $(0.0001)^{* *}$ & $(0.0001)^{* *}$ & $(0.0003)^{*}$ & $(0.0003)^{*}$ \\
\hline \multirow{2}{*}{ Return migrant } & -0.074 & -0.107 & -0.159 & -0.159 \\
\hline & $(0.032)^{* *}$ & $(0.041)^{* * *}$ & $(0.047)^{* * *}$ & $(0.047)^{* * *}$ \\
\hline \multicolumn{5}{|l|}{ Probability of Emigration } \\
\hline \multirow[t]{2}{*}{ Oil price } & 0.001 & 0.001 & 0.001 & 0.001 \\
\hline & $(0.000)^{* * *}$ & $(0.000)^{* * *}$ & $(0.000)^{* * *}$ & $(0.000)^{* * *}$ \\
\hline \multicolumn{5}{|l|}{ Probability of Return Migration } \\
\hline \multirow[t]{2}{*}{ Shocks } & 0.148 & 0.148 & 0.148 & 0.148 \\
\hline & $(0.009)^{* * *}$ & $(0.009)^{* * *}$ & $(0.009)^{* * *}$ & $(0.009)^{* * *}$ \\
\hline \multirow[t]{2}{*}{ sigma_1 } & -2.204 & -1.846 & -1.557 & -1.557 \\
\hline & $(0.049) * * *$ & $(0.032)^{* * *}$ & $(0.053)^{* * *}$ & $(0.053)^{* * *}$ \\
\hline \multirow[t]{2}{*}{ sigma_2 } & -0.874 & -0.874 & -0.874 & -0.874 \\
\hline & $(0.006)^{* * *}$ & $(0.006)^{* * *}$ & $(0.006)^{* * *}$ & $(0.006)^{* * *}$ \\
\hline \multirow[t]{2}{*}{ sigma_3 } & -1.100 & -1.100 & -1.100 & -1.100 \\
\hline & $(0.014)^{* * *}$ & $(0.014)^{* * *}$ & $(0.014)^{* * *}$ & $(0.014)^{* * *}$ \\
\hline \multirow[t]{2}{*}{ rho_12 } & 0.253 & 0.251 & 0.337 & 0.337 \\
\hline & $(0.124)^{* *}$ & $(0.110)^{* *}$ & $(0.096)^{* * *}$ & $(0.095)^{* * *}$ \\
\hline \multirow[t]{2}{*}{ rho_13 } & 0.256 & 0.246 & 0.322 & 0.321 \\
\hline & $(0.107)^{* *}$ & $(0.097)^{* *}$ & $(0.092)^{* * *}$ & $(0.092)^{* * *}$ \\
\hline \multirow[t]{2}{*}{ rho_23 } & 1.388 & 1.388 & 1.387 & 1.387 \\
\hline & $(0.037)^{* * *}$ & $(0.037)^{* * *}$ & $(0.037)^{* * *}$ & $(0.037)^{* * *}$ \\
\hline $\mathrm{N}$ & 4,098 & 4,098 & 4,098 & 4,098 \\
\hline
\end{tabular}

Notes. (I) All specifications are weighted by the sampling weights provided in the dataset, with robust standard errors. (II) The selection equations are based on full sample of 13,943 individuals. (III) Data source: JLMPS, 2010. 
Table 10: Return migration and female labour force participation

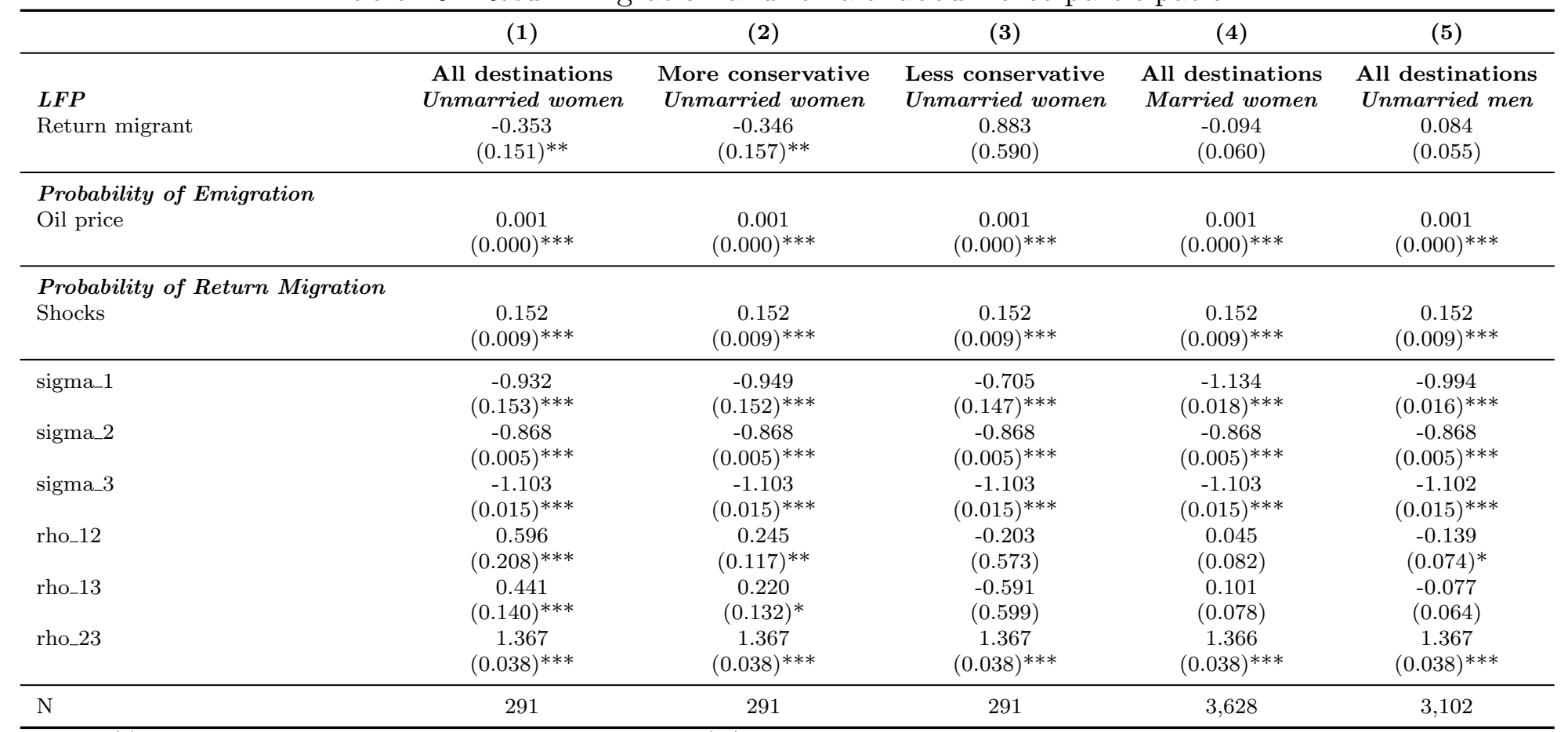

Notes. (I) Dep. var. is participation to the labour force. (II) All specifications are weighted by the sampling weights provided in the dataset, with robust standard errors. (III) The selection equations are based on full sample of 13,943 individuals. (IV) Data source: JLMPS, 2010. 
Table 11: Return migration and daughters' dropout from education

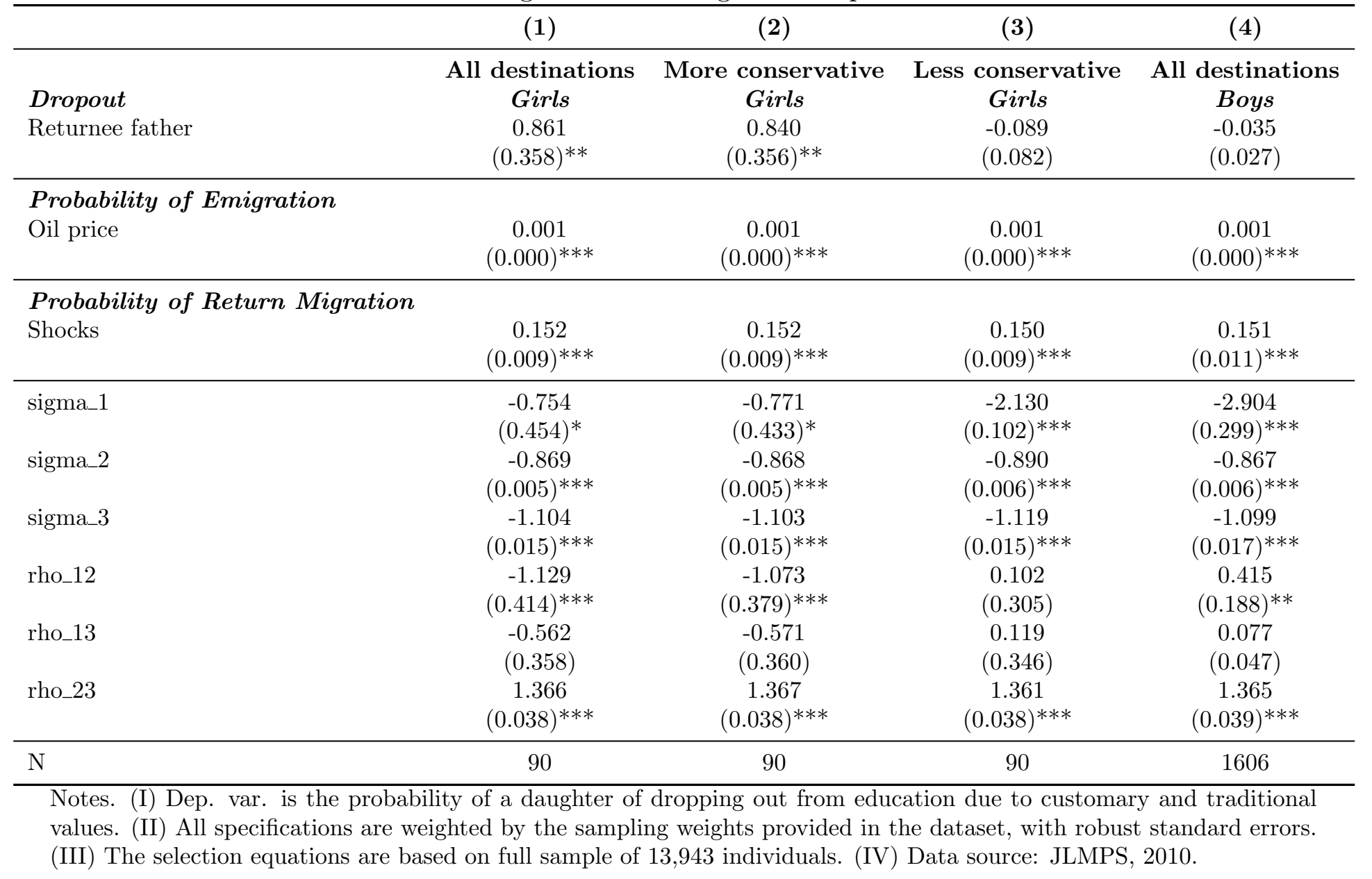


Table 12: Return migration and wives' fertility

\begin{tabular}{|c|c|c|c|c|}
\hline & (1) & (2) & (3) & (4) \\
\hline Fertility & All destinations & All destinations & More conservative & Less conservative \\
\hline Returnee husband & $\begin{array}{c}0.125 \\
(0.059)^{* *}\end{array}$ & $\begin{array}{c}1.444 \\
(0.580)^{* *}\end{array}$ & $\begin{array}{c}1.473 \\
(0.593)^{* *}\end{array}$ & $\begin{array}{c}1.963 \\
(1.599)\end{array}$ \\
\hline $\begin{array}{l}\text { Probability of Emigration } \\
\text { Oil price }\end{array}$ & $\begin{array}{c}0.001 \\
(0.000)^{* * *}\end{array}$ & $\begin{array}{c}0.001 \\
(0.000)^{* * *}\end{array}$ & $\begin{array}{c}0.001 \\
(0.000)^{* * *}\end{array}$ & $\begin{array}{c}0.001 \\
(0.000)^{* * *}\end{array}$ \\
\hline $\begin{array}{l}\text { Probability of Return Migration } \\
\text { Shocks }\end{array}$ & $\begin{array}{c}0.144 \\
(0.015)^{* * *}\end{array}$ & $\begin{array}{c}0.143 \\
(0.015)^{* * *}\end{array}$ & $\begin{array}{c}0.143 \\
(0.015)^{* * *}\end{array}$ & $\begin{array}{c}0.143 \\
(0.015)^{* * *}\end{array}$ \\
\hline sigma_1 & $\begin{array}{c}-1.570 \\
(0.149)^{* * *}\end{array}$ & $\begin{array}{c}0.897 \\
(0.057)^{* * *}\end{array}$ & $\begin{array}{c}0.911 \\
(0.063)^{* * *}\end{array}$ & $\begin{array}{c}1.055 \\
(0.105)^{* * *}\end{array}$ \\
\hline sigma_2 & $\begin{array}{c}-0.838 \\
(0.012)^{* * *}\end{array}$ & $\begin{array}{c}-0.839 \\
(0.012)^{* * *}\end{array}$ & $\begin{array}{c}-0.839 \\
(0.012)^{* * *}\end{array}$ & $\begin{array}{c}-0.839 \\
(0.012)^{* * *}\end{array}$ \\
\hline sigma_3 & $\begin{array}{c}-0.969 \\
(0.022)^{* * *}\end{array}$ & $\begin{array}{c}-0.970 \\
(0.022)^{* * *}\end{array}$ & $\begin{array}{c}-0.970 \\
(0.022)^{* * *}\end{array}$ & $\begin{array}{c}-0.970 \\
(0.022)^{* * *}\end{array}$ \\
\hline rho_12 & $\begin{array}{c}-0.473 \\
(0.179)^{* * *}\end{array}$ & $\begin{array}{c}-0.358 \\
(0.136)^{* * *}\end{array}$ & $\begin{array}{c}-0.373 \\
(0.138) * * *\end{array}$ & $\begin{array}{l}-0.170 \\
(0.308)\end{array}$ \\
\hline rho_13 & $\begin{array}{c}-0.304 \\
(0.131)^{* *}\end{array}$ & $\begin{array}{c}-0.274 \\
(0.111)^{* *}\end{array}$ & $\begin{array}{c}-0.264 \\
(0.112)^{* *}\end{array}$ & $\begin{array}{l}-0.414 \\
(0.292)\end{array}$ \\
\hline rho_23 & $\begin{array}{c}1.474 \\
(0.067)^{* * *}\end{array}$ & $\begin{array}{c}1.473 \\
(0.067)^{* * *}\end{array}$ & $\begin{array}{c}1.472 \\
(0.067)^{* * *}\end{array}$ & $\begin{array}{c}1.473 \\
(0.067)^{* * *}\end{array}$ \\
\hline $\mathrm{N}$ & 1,142 & 1,142 & 1,142 & 1,142 \\
\hline
\end{tabular}

Notes. (I) Dep. var. in column 1 is the probability of having at least one child, whilst dep. var in columns 2 to 4 is the number of children. (II) All specifications are weighted by the sampling weights provided in the dataset, with robust standard errors. (III) The selection equations are based on full sample of 13,943 individuals. The sample of women is restricted to those 40 years of age or more. (IV) Data source: JLMPS, 2010. 
Table 13: Average predicted values

\begin{tabular}{|c|c|c|c|c|c|c|}
\hline & Simple average & All (Combined) & With returnee & Without migrant & Difference (\%) & P-value \\
\hline Probability of being in the labour force & 0.158 & 0.161 & 0.111 & 0.246 & -0.55 & 0.00 \\
\hline Probability of dropping out from education & 0.093 & 0.010 & 0.565 & 0.114 & 3.96 & 0.00 \\
\hline Probability of having at least one child & 0.933 & 0.861 & 1.169 & 0.819 & 0.43 & 0.00 \\
\hline
\end{tabular}

Notes. (I) P-value reports the results of a t test of Ho: Return migration=Non-migrants. (II) The sample size is respectively $\mathrm{N}=291$ for labour force participation, $\mathrm{N}=90$ for dropping out, and $\mathrm{N}=1142$ for fertility. (III) Values are weighted by the sampling weights provided in the dataset. (IV) Data source: JLMPS, 2010. 


\section{Appendix}

Table 14: Variables included in RWI and respective weights

\begin{tabular}{|c|c|c|c|c|}
\hline Variable & Categories & EQUAL & PCA & MCA \\
\hline \multirow[t]{2}{*}{ Place of a woman should not only be the house, she should be allowed to work } & Agree & 0.1 & 0.3949 & 0.079 \\
\hline & Disagree & & & -0.812 \\
\hline \multirow[t]{2}{*}{ A husband should help the working mother in taking care of the children } & Agree & 0.1 & 0.3855 & 0.055 \\
\hline & Disagree & & & -1.109 \\
\hline \multirow{2}{*}{ A husband should help the working wife in housework } & Agree & 0.1 & 0.3390 & 0.084 \\
\hline & Disagree & & & -0.560 \\
\hline \multirow{2}{*}{ Female education should be to get jobs, not only to become good wives/mothers } & Agree & 0.1 & 0.1112 & 0.063 \\
\hline & Disagree & & & -0.080 \\
\hline \multirow[t]{2}{*}{ The woman working outside home can be a good mother } & Agree & 0.1 & 0.2489 & 0.069 \\
\hline & Disagree & & & -0.370 \\
\hline \multirow[t]{2}{*}{ Women should work in order to be financially independent } & Agree & 0.1 & 0.1643 & 0.088 \\
\hline & Disagree & & & -0.126 \\
\hline \multirow[t]{2}{*}{ Female work doesn't contradict with ability to build good relationship with husband } & Agree & 0.1 & 0.2481 & 0.092 \\
\hline & Disagree & & & -0.276 \\
\hline \multirow[t]{2}{*}{ Women should get leadership positions in the society } & Agree & 0.1 & 0.3071 & 0.089 \\
\hline & Disagree & & & -0.437 \\
\hline \multirow[t]{2}{*}{ I do not mind if boys and girls get the same level of education } & Agree & 0.1 & 0.4028 & 0.026 \\
\hline & Disagree & & & -2.547 \\
\hline \multirow[t]{2}{*}{ Boys and girls should be treated equally } & Agree & 0.1 & 0.4014 & 0.023 \\
\hline & Disagree & & & -2.856 \\
\hline
\end{tabular}


Table 15: Variables included in FMI and respective weights

\begin{tabular}{|c|c|c|c|c|}
\hline Variable & Categories & EQUAL & PCA & MCA \\
\hline You can go to the market without permission & $\begin{array}{c}\text { Agree } \\
\text { Disagree }\end{array}$ & 0.25 & 0.5009 & $\begin{array}{c}0.186 \\
-3.522\end{array}$ \\
\hline You can go to the doctor for treatment without permission & $\begin{array}{c}\text { Agree } \\
\text { Disagree }\end{array}$ & 0.25 & 0.5140 & $\begin{array}{c}0.192 \\
-3.590\end{array}$ \\
\hline You can go to take one of the children to the doctor without permission & $\begin{array}{c}\text { Agree } \\
\text { Disagree }\end{array}$ & 0.25 & 0.4927 & $\begin{array}{c}0.197 \\
-3.217\end{array}$ \\
\hline You can visit a relative, friend or neighbour without permission & $\begin{array}{c}\text { Agree } \\
\text { Disagree }\end{array}$ & 0.25 & 0.4921 & $\begin{array}{r}0.186 \\
-3.408\end{array}$ \\
\hline
\end{tabular}

Notes. Source: JLMPS, 2010. 
Table 16: Variables included in DMPI and respective weights

\begin{tabular}{|c|c|c|c|c|}
\hline Variable & Categories & EQUAL & PCA & MCA \\
\hline \multirow[t]{2}{*}{ In your family you usually have the final say in making large household purchases } & Agree & 0.11 & 0.3193 & 1.174 \\
\hline & Disagree & & & -0.115 \\
\hline \multirow[t]{2}{*}{ In your family you usually have the final say in making household purchases for daily needs } & Agree & 0.11 & 0.3495 & 0.881 \\
\hline & Disagree & & & -0.183 \\
\hline \multirow[t]{2}{*}{ In your family you usually have the final say in visiting family, friends or relatives } & Agree & 0.11 & 0.3108 & 0.856 \\
\hline & Disagree & & & -0.149 \\
\hline \multirow[t]{2}{*}{ In your family you usually have the final say in choosing what food should be cooked each day } & Agree & 0.11 & 0.3083 & 0.405 \\
\hline & Disagree & & & -0.310 \\
\hline \multirow[t]{2}{*}{ In your family you usually have the final say in getting medical treatment or advice for yourself } & Agree & 0.11 & 0.3489 & 0.466 \\
\hline & Disagree & & & -0.345 \\
\hline \multirow[t]{2}{*}{ In your family you usually have the final say in buying clothes for yourself } & Agree & 0.11 & 0.2831 & 0.248 \\
\hline & Disagree & & & -0.427 \\
\hline \multirow[t]{2}{*}{ In your family you usually have the final say in taking the children to the doctor } & Agree & 0.11 & 0.3874 & 0.836 \\
\hline & Disagree & & & -0.237 \\
\hline \multirow[t]{2}{*}{ In your family you usually have the final say in sending the children to school } & Agree & 0.11 & 0.2954 & 0.775 \\
\hline & Disagree & & & -0.149 \\
\hline \multirow[t]{2}{*}{ In your family you usually have the final say in buying clothes for the children } & Agree & 0.11 & 0.3808 & 0.698 \\
\hline & Disagree & & & -0.275 \\
\hline
\end{tabular}


Table 17: The relationship between historical real oil prices and women's labour force participation and gender norms in 2010

\begin{tabular}{|c|c|c|}
\hline & LFP & RWI (pca) \\
\hline Oil price & $\begin{array}{c}-0.001 \\
(0.000)\end{array}$ & $\begin{array}{c}0.000 \\
(0.000)\end{array}$ \\
\hline Basic education & $\begin{array}{c}0.038 \\
(0.027)\end{array}$ & $\begin{array}{c}0.009 \\
(0.010)\end{array}$ \\
\hline Secondary education & $\begin{array}{l}-0.014 \\
(0.029)\end{array}$ & $\begin{array}{c}0.013 \\
(0.010)\end{array}$ \\
\hline Post secondary education & $\begin{array}{c}0.515 \\
(0.035)^{* * *}\end{array}$ & $\begin{array}{c}0.041 \\
(0.010)^{* * *}\end{array}$ \\
\hline Rural & $\begin{array}{c}0.000 \\
(0.024)\end{array}$ & $\begin{array}{c}0.006 \\
(0.006)\end{array}$ \\
\hline Age & $\begin{array}{c}0.054 \\
(0.006)^{* * *}\end{array}$ & $\begin{array}{l}-0.003 \\
(0.002)\end{array}$ \\
\hline Age squared & $\begin{array}{c}-0.077 \\
(0.008)^{* * *}\end{array}$ & $\begin{array}{c}0.003 \\
(0.002)\end{array}$ \\
\hline Mother's edu basic & $\begin{array}{c}0.054 \\
(0.030)^{*}\end{array}$ & $\begin{array}{c}0.021 \\
(0.007)^{* * *}\end{array}$ \\
\hline Mother's edu secondary & $\begin{array}{c}0.018 \\
(0.037)\end{array}$ & $\begin{array}{c}-0.001 \\
(0.009)\end{array}$ \\
\hline Mother's edu post secondary & $\begin{array}{l}-0.010 \\
(0.043)\end{array}$ & $\begin{array}{c}0.017 \\
(0.009)^{*}\end{array}$ \\
\hline Asset index & $\begin{array}{c}0.049 \\
(0.169)\end{array}$ & $\begin{array}{c}0.109 \\
(0.039)^{* * *}\end{array}$ \\
\hline Constant & $\begin{array}{c}-0.664 \\
(0.125)^{* * *}\end{array}$ & $\begin{array}{c}0.863 \\
(0.033)^{* * *}\end{array}$ \\
\hline Governorate FE & Yes & Yes \\
\hline $\mathrm{R} 2$ & 0.39 & 0.07 \\
\hline $\mathrm{N}$ & 1,948 & 1,948 \\
\hline
\end{tabular}

Notes. (I) Dep. var. in column 1 is the probability of being in the labour force, whilst dep. var in columns 2 is the self-perceived Role of Women Index. (II) All specifications are weighted by the sampling weights provided in the dataset, with robust standard errors. (III) Data source: JLMPS, 2010. 
Table 18: Characteristics of returnees and non-migrants

\begin{tabular}{lccl}
\hline & Non-Migrant & Returnee & t-Test \\
\hline Employment status & 0.38 & 0.42 & $(-3.03)^{* *}$ \\
Less than basic education & 0.19 & 0.16 & $(2.64)^{* *}$ \\
Basic education & 0.41 & 0.27 & $(10.75)^{* * *}$ \\
Secondary education & 0.20 & 0.25 & $(-4.33)^{* * *}$ \\
Post-secondary education & 0.20 & 0.32 & $(-11.06)^{* * *}$ \\
Married & 0.51 & 0.68 & $(-12.68)^{* * *}$ \\
Consanguinity & 0.14 & 0.19 & $(-4.48)^{* * *}$ \\
Rural areas & 0.31 & 0.09 & $(18.64)^{* * *}$ \\
Age & 30.47 & 38.12 & $(-23.78)^{* * *}$ \\
Age squared & 10.65 & 16.18 & $(-24.57)^{* * *}$ \\
Children & 0.92 & 0.94 & $(-1.78)$ \\
Mother's education & 1.94 & 2.10 & $(-4.66)^{* * *}$ \\
\hline N & 12425 & 1518 & \\
\hline
\end{tabular}

Notes. Source: JLMPS, 2010. 


\begin{tabular}{lcc}
\hline \multirow{4}{*}{ Oil price } & Probability of Return Migration & Probability of Emigration \\
& -0.000 & 0.002 \\
Shocks & $(0.000)$ & $(0.000)^{* * *}$ \\
& 0.075 & -0.016 \\
Controls & $(0.008)^{* * *}$ & $(0.018)$ \\
\hline R2 & Yes & Yes \\
N & 0.18 & 0.30 \\
\hline
\end{tabular}

Source: JLMPS, 2010. 
Table 20: Robustness check - Heckman selection

\begin{tabular}{lcc}
\hline & $(1)$ & $(2)$ \\
\hline \multirow{3}{*}{ Oil price } & Probability of Return Migration & Probability of Emigration \\
& & 0.007 \\
Shocks & 0.104 & $(12.55)^{* * *}$ \\
& $(7.36)^{* * *}$ & \\
Mills & 0.618 & \\
& $(12.65)^{* * *}$ & \\
\hline$\chi^{2}(18)=1156.26$ & Prob $>\chi^{2}=0.000$ & \\
Observations & 13,943 & \\
\hline
\end{tabular}

Source: JLMPS, 2010. 
Table 21: Robustness check - Single variables

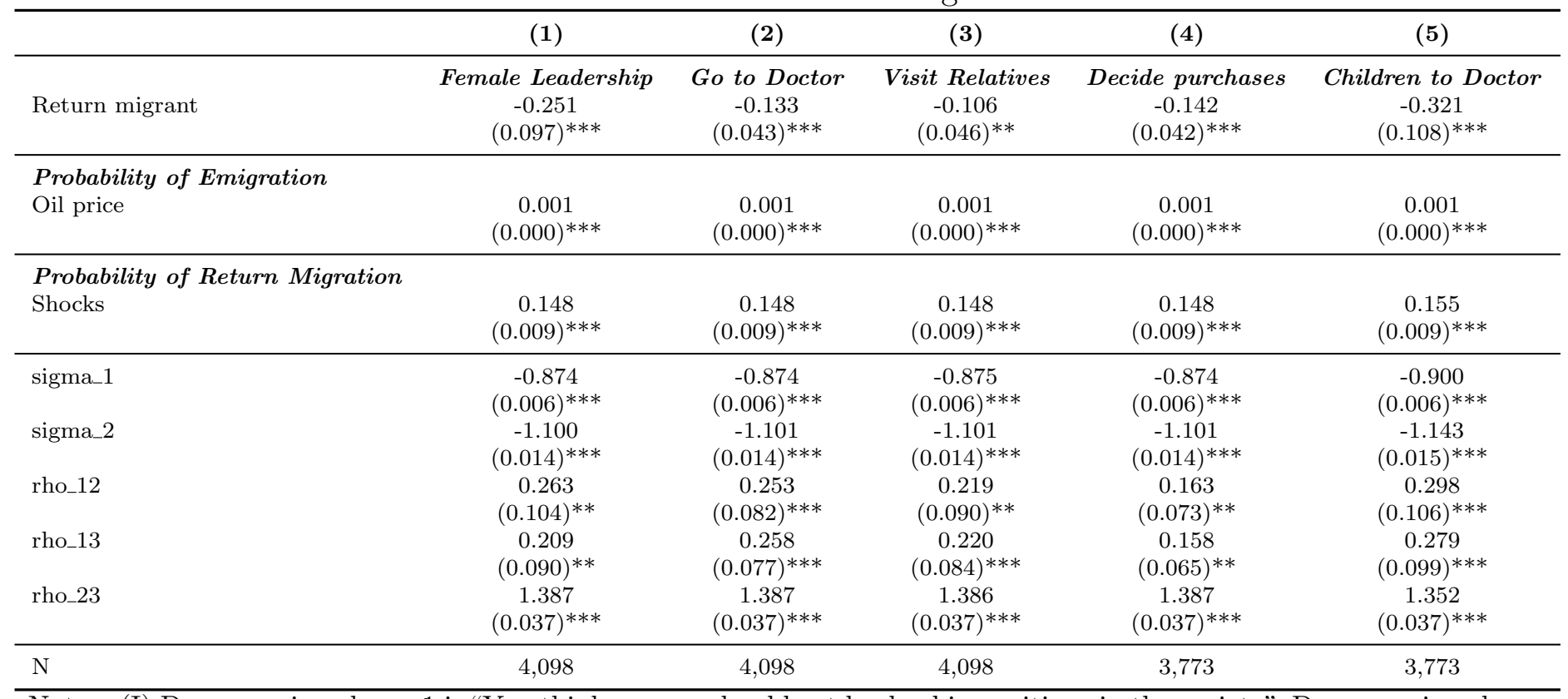

Notes. (I) Dep. var. in column 1 is "You think women should get leadership positions in the society"; Dep. var. in column 2 is "You can go to the doctor for treatment without permission"; Dep. var. in column 3 is "You can visit a relative, friend or neighbour without permission"; Dep. var. in column 4 is "In your family you usually have the final say in making large household purchases"; Dep. var. in column 5 is "In your family you usually have the final say in taking the children to the doctor". (II) All specifications are weighted by the sampling weights provided in the dataset, with robust standard errors. (III) The selection equations are based on full sample of 13,943 individuals. (IV) Data source: JLMPS, 2010. 
Table 22: Average predicted values - Composite index and single variables

\begin{tabular}{|c|c|c|c|c|c|c|}
\hline & Simple average & All (Combined) & With returnee & Without migrant & Difference (\%) & P-value \\
\hline \multicolumn{7}{|c|}{ Female Empowerment Index } \\
\hline RWI & 0.932 & 0.928 & 0.884 & 0.939 & -0.06 & 0.00 \\
\hline FMI & 0.052 & 0.077 & 0.001 & 0.097 & -0.98 & 0.00 \\
\hline DMPI & 0.257 & 0.331 & 0.252 & 0.351 & -0.28 & 0.00 \\
\hline \multicolumn{7}{|l|}{ Single Indicators } \\
\hline Female leadership & 0.801 & 0.822 & 0.648 & 0.867 & -0.25 & 0.00 \\
\hline Go to doctor & 0.062 & 0.077 & 0.002 & 0.097 & -0.98 & 0.00 \\
\hline Visit relatives & 0.062 & 0.073 & 0.009 & 0.089 & -0.90 & 0.00 \\
\hline Decide purchase & 0.077 & 0.108 & 0.003 & 0.112 & -0.97 & 0.00 \\
\hline Children to doctor & 0.312 & 0.333 & 0.121 & 0.387 & -0.69 & 0.00 \\
\hline
\end{tabular}

Notes. (I) P-value reports the results of a t test of Ho: Return migration=Non-migrants. (II) Values are weighted by the

sampling weights provided in the dataset. (III) Results based on a full sample of women of $N=4098$. (IV) Data source: JLMPS, 2010. 
Table 23: Robustness check - Reference year for historical oil price

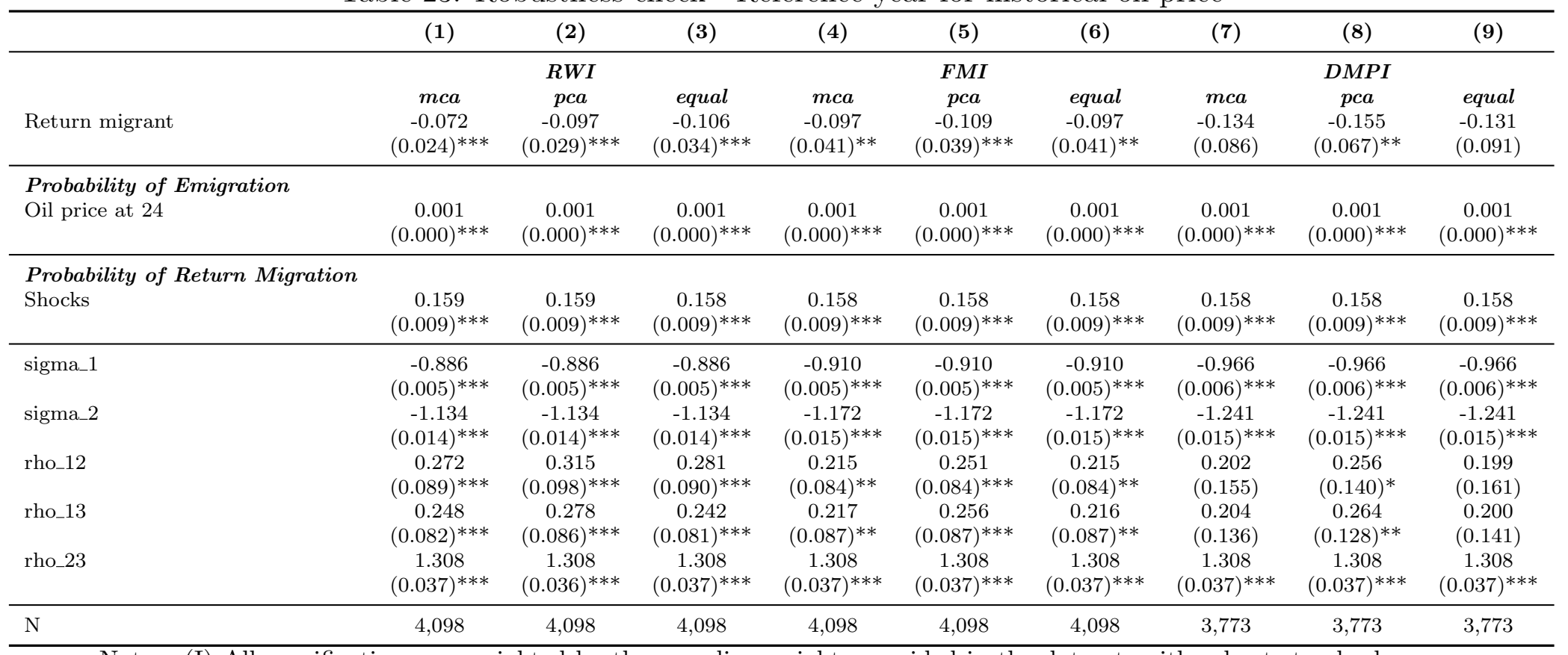

Notes. (I) All specifications are weighted by the sampling weights provided in the dataset, with robust standard errors.

(II) The selection equations are based on full sample of 13,943 individuals. (III) Data source: JLMPS, 2010. 
Table 24: Robustness checks - Different exclusion restriction for probability of emigration

\begin{tabular}{lccc}
\hline & $(1)$ & $(2)$ & $(3)$ \\
\hline \multirow{2}{*}{ Return migrant } & $\boldsymbol{R W I}$ & $\boldsymbol{F M I}$ & $\boldsymbol{D} \boldsymbol{M P I}$ \\
& -0.052 & -0.204 & -0.163 \\
& $(0.026)^{* *}$ & $(0.072)^{* * *}$ & $(0.064)^{* *}$ \\
\hline Probability of Emigration & & & \\
Attractiveness & 0.177 & 0.225 & 0.172 \\
& $(0.084)^{* *}$ & $(0.085)^{* * *}$ & $(0.084)^{* *}$ \\
\hline Probability of Return Migration & & & \\
Shocks & 0.203 & 0.203 & 0.203 \\
& $(0.011)^{* * *}$ & $(0.011)^{* * *}$ & $(0.011)^{* * *}$ \\
\hline sigma_1 & -2.105 & -1.546 & -1.549 \\
& $(0.026)^{* * *}$ & $(0.090)^{* * *}$ & $(0.058)^{* * *}$ \\
sigma_2 & -0.847 & -0.847 & -0.847 \\
sigma_3 & $(0.006)^{* * *}$ & $(0.006)^{* * *}$ & $(0.006)^{* * *}$ \\
& -1.172 & -1.172 & -1.172 \\
rho_12 & $(0.014)^{* * *}$ & $(0.014)^{* * *}$ & $(0.014)^{* * *}$ \\
& 0.136 & 0.543 & 0.307 \\
rho_13 & $(0.094)$ & $(0.183)^{* * *}$ & $(0.145)^{* *}$ \\
& 0.146 & 0.411 & 0.275 \\
rho_23 & $(0.080)^{*}$ & $(0.121)^{* * *}$ & $(0.125)^{* *}$ \\
& 1.231 & 1.229 & 1.230 \\
N & $(0.035)^{* * *}$ & $(0.035)^{* * *}$ & $(0.035)^{* * *}$ \\
\hline Notes. (I) & 4,098 & 4,098 & 3,773 \\
\hline
\end{tabular}

Notes. (I) All specifications are weighted by the sampling weights provided in the dataset, with robust standard errors. (II) The selection equations are based on full sample of 13,943 individuals. (III) Data source: JLMPS, 2010. 